\title{
APPLIED RESEARCH ON BANKING PRODUCTION PLANNING AND CONTROL IN THE HOUSING INVESTMENT PROCESS
}

Luiz Fernando de Lyra Novaes luiz@avalsoft.com.br CAIXA - Brazilian Federal Saving Bank, Rio de Janeiro, RJ, Brazil.

\section{Sergio Antão Paiva} sergioantao51@gmail.com CAIXA - Brazilian Federal Saving Bank, Rio de Janeiro, RJ, Brazil.

Fabio Matera Barbosa fabiomatera@gmail.com CAIXA - Brazilian Federal Saving Bank, Rio de Janeiro, RJ, Brazil.

Helaine Coutinho Cardoso helaine.cardoso@gmail.com CAIXA - Brazilian Federal Saving Bank, Rio de Janeiro, RJ, Brazil.

Ives Yokoyama de Almeida ives.yokoyama@gmail.com CAIXA - Brazilian Federal Saving Bank, Rio de Janeiro, RJ, Brazil.

Thomas Campos Silva de Lyra Novaes

thomasnovaes@yahoo.com.br Norwegian Business School, Oslo, Norway.

\section{ABSTRACT}

Goal: This article presents a PMM - Performance Measurement and Management system which analyzes 72 regional managerial offices (RMO) found on the database of a banking institution. Each of the offices has a portfolio of investments in real estates in Brazil financed by the Banking Institution. The PMM gives diagnosis of the performance of each of these offices through a data mining procedure from the years 2015 to 2017 and suggest on how the worst performing offices can replicate the best performing ones. Design / Methodology / Approach: The PMM was designed to estimate an efficient model by Data Envelopment Analysis (DEA). Ranks the efficiency of the RMOs and provides managerial solutions with the background information upon which to base decisions. Results: The proposed PMM is a new approach paradigm to institution, in the way to set the best results on account of resources available. The current method used per the Institution sets effectiveness targets without accounting the resources spent.

Limitations of the investigation: The restrictions in time and resources did not make possible compare the current organizational method with the proposed PMM. A main question was not answered if the effectiveness RMOs are efficient too, or, vice-versa.

Practical implications: The design of PMM has the ability to enable the institution of processing a more flexible and dynamic performance management. The practical implications achieved are reported in systematic analysis approach that testify the quality and effectiveness of this PMM modeling in conclusion section at table of Lenses of Systematic Analysis.

Originality / Value: This article is innovative as it introduces the ability to perform simulations in the DEA environment, principally because its possibility to rearrange the modeling from the evolution of institution performance. Also, the corporate aspect of adopting a universalized methodology for evaluating efficiency.

Keywords: Data Envelopment Analysis; Performance Measurement and Management System; Simulation; Data Mining; Banking Industry. 


\section{INTRODUCTION}

This paper intends to propose a complementary model to a Bank Institution, that provides a performance management background information, upon which each management unit to base self-decisions. The proposal of PMM - Performance Measurement and Management system promotes organizational learning on portraying the best results of own benchmark units. It sets the best practice to improve productivity of the inefficient units from available resources.

This methodology is designed to answer the question of why, given the same portfolio of investments, some decision-making units (DMU) outperform others (Charnes et al., 1978). Another target is to describe what the other DMU or RMO can do to replicate the best performing ones (Camioto et al., 2017).

The PMM was designed according to the Systemic Analysis developed by Valmorbida and Ensslin (2016) and applied by Franco et al. (2016), refer to section 2 - literature review. The objective of the study developed by Franco et al. (2016) was to know what the international scientific literature presents about the subject of Performance Evaluation and Management. Thus, to identify gaps and opportunities for improvement in Performance Measuring and Management theory as stated in the Bibliographic Portfolio studied and synthesized in the lenses, refer to Table 1. In order to define quality and effectiveness of the PMM developed.

The performance modeling system for measuring and managing the relative efficiency and potential improvement capabilities is applied to seventy-two Regional Managerial Offices (RMO) by identifying their strengths and weaknesses.

Each RMO has autonomous management and the Central Administration has the task of leader all areas of corporate environment promoting its guidelines, regulation, instrumentalization and organizing of $\mathrm{TI}$ and all processes, also more to foster the organizational compliance.

The Institution have been in use a performance management system based on the effectiveness to reach a range of targets, that report some RMO results. On this way, the main criteria are the metric with account of the customer satisfaction, other metric with account of the total value of housing mortgage credit contracts and another with account of the compliance with Federal Institutional Controllers.

The complexity in implement organizational performance management systems (PMSs) is consequent of the difficulty on implementing efficacious management systems faced with the growing environmental and organizational complexity
Table 1 - Lenses of Systemic Analysis

\begin{tabular}{|c|c|}
\hline \multicolumn{2}{|c|}{ Systemic Analysis / Lenses of Gaps (1) and Improvements (2) } \\
\hline $\begin{array}{l}\text { Approach } \\
\text { Lens }\end{array}$ & $\begin{array}{l}\text { 1. Built and maintained to measure the } \\
\text { effectiveness of the results obtained by the units } \\
\text { evaluated. } \\
\text { 2. Measure efficiency by accounting for costs } \\
\text { and results amplified by considering Exogenous } \\
\text { Inputs (external environmental variables). }\end{array}$ \\
\hline $\begin{array}{l}\text { Singularity } \\
\text { Lens }\end{array}$ & $\begin{array}{l}\text { 1. Manager does not participate in the design in } \\
\text { order to identify the relevant products, inputs } \\
\text { and just in time report. } \\
\text { 2. Designed in order to evolve and adapt to } \\
\text { changes in the internal environment with } \\
\text { participation of the manager. }\end{array}$ \\
\hline $\begin{array}{l}\text { Identification } \\
\text { Lens }\end{array}$ & $\begin{array}{l}\text { 1. Manager has a limited view of } \\
\text { organizational-environment knowledge. His values } \\
\text { and requirements are not taken into account when } \\
\text { applying criteria that are important to measure. } \\
\text { 2. Promote a continuous self-knowledge by } \\
\text { reporting of what occurs into the reference units } \\
\text { in a holistic view. }\end{array}$ \\
\hline $\begin{array}{l}\text { Measuring } \\
\text { Lens }\end{array}$ & $\begin{array}{l}\text { 1. The weights to performer the goals are } \\
\text { subjective defined. } \\
\text { 2. DEA weights are defined by a programming } \\
\text { problem. }\end{array}$ \\
\hline $\begin{array}{l}\text { Integration } \\
\text { Lens }\end{array}$ & $\begin{array}{l}\text { 1. Current integration and processing enable } \\
\text { holistic and systematic insight into certain } \\
\text { time-lagged goals. } \\
\text { 2. Design the application and processing that allow } \\
\text { for holistic and systematic vision just in time. }\end{array}$ \\
\hline $\begin{array}{l}\text { Management } \\
\text { Lens }\end{array}$ & $\begin{array}{l}\text { 1. Current system doesn ‘t diagnose unit's } \\
\text { strengths and weaknesses neither establish } \\
\text { performance improvement actions. } \\
\text { 2. Design a system that diagnoses each unit's } \\
\text { strengths and weaknesses and establish } \\
\text { performance improvement actions. }\end{array}$ \\
\hline
\end{tabular}

(Okwir, 2018). Thus, by understanding how this complexity evolves, organizations can support the process stages by developing 'best practices' in measuring and managing the performance (Bourne et al., 2005; Melnyk et al., 2014; Nudurupati et al., 2011). The PMM - Performance Management and Measurement system literature also refers to complexity when it addresses the evolution of PMSs. For instance, Bititci et al. (2012) reveal business trends, how PMM is moving towards challenging operational contexts, thus suggesting that it is a self-learning system.

Our proposal to solve the described contextualization of the complexity in implement organizational PMM at the initial's paragraphs, took place, firstly, by gathering a group of the banking institution employees with technical experience on manage real estate portfolios. Some work in the RMOs and others in Central Administration. 
Contemporary literature on performance analysis was researched Coelli et al. (2005), Tabatabaei and Bazrkar (2019), Fethi and Pasiouras (2010), Maniati and Sambracos (2017), Ray (2004) and Camioto et al. (2017). On this way, the WG concludes that to the specific objectives of this article, the Data Envelopment Analysis (DEA) is a superior method of performance assessment than the other usual methods (Economic Method of Least Squares (LSQ), Total Factor Productivity (TFP) and Stochastic Frontiers (SF).

The rest of the paper is organized as follows. The next sections present the PMM literature review, followed by presentation of the DEA methodology, the background of the Institution with the current Effectiveness Performance System, that is based on effectiveness targets, the modeling of a complementary Performance Measuring and Management System that accounts the resource and results spent, simulating the PMM operations with a thorough discussion. Finally, conclusion highlights the summary of the findings and key contributions, which is followed by the limitations of this study and future avenues of research.

\section{LITERATURE REVIEW}

This review has been done by multidisciplinary team of specialists of CAIXA ECONÔMICA FEDERAL, refer to section 4 , with diversified formation and work experience, led by the authors of this paper. The main objective was to demonstrate the potential of a PMM - Performance Measurement and Management system of introducing a new approach to the institution, that will permit a more dynamic adjustment of performance goals.

Performance is measured not only to find out how well processes are performed, but also to locate where development efforts should be directed and how the possibilities for improvements are evaluated (Koota and Takala, 1998). Global competition in major companies, in the sense of a renewed commitment to production excellence, has its attention focused on the quality of products and processes, inventory levels and improvement through workforce training, trying to provide a competitive advantage for businesses in order to become world-class (Gunasekaran et al., 2005).

At this perspective the literatures reviews showed that both the information and behavioral perspectives (separately or together) can be used to study and justify the use of PMS in organizations (Schiehll and Morissette, 2000). The relation between the degree of reliance on accounting information for performance assess and individual behavior (functional or dysfunctional) has been examined in behavioral accounting research. The information perspective, on the other hand, studies how an organization's ability to function successfully depends on the availability of information, which properly track business performance upon which its managers can act.

Melnyk et al., 2014 addresses the issue that companies have begun to verify performance measurement as a tool used to quantify the efficiency and / or effectiveness of the action, making processes and activities quantifiable and verifiable from this point of view. They present an analysis of the components of the performance appraisal system: performance measurement and performance management. The authors state that performance appraisal is a social phenomenon, so appraisal models should recognize the feelings, values, beliefs and perceptions of individuals in the organization and stakeholders (Bititci et al., 2012).

The PMM literatures observed that the most of Performance management systems (PMS) are still resilient to changes in the internal and external environment of the firm (Nudurupati et al., 2011), concluding that them still are not have a dynamic process. The question is, some of organizations operating in dynamic markets are addressing static PMS while working on dynamic strategies, resulting in complexity and a lack of efficiency in resource allocation (Okwir, 2018).

At a complementary point of view, Fethi and Pasiouras (2010) cited researchers with skills and expertise in Corporate Finance, Banking Industry, Econometric Modeling, Efficiency Analysis, Operational Research and correlated knowledge. The paper presents a comprehensive review of 196 studies that employ operational research (O.R.) and Artificial Intelligence (A.I.) techniques in the assessment of bank performance, considering that bank efficiency involves both parametric and non-parametric methods. They observe that the most frequently used non-parametric method is Data Envelopment Analysis (DEA).

Banker and Morey (1986) discussed an important question, is DEA be able to ensure units to be compared with peers operating in a more favorable environment by incorporate environmental variables. To be feasible, it is required that the environmental variables are been ordered from the least to the most harmful ones for efficiency. Then, the efficiency of a given firm is compared with those firms in the sample that have a value of the environmental variable, in which the range contains the given firm. This principle was adopted in the modeling procedures of this paper.

Maniati and Sambracos (2017) applied DEA method, selected as the most suitable for the measurement of technical efficiency of a group of banks, as can process models with many inputs and outputs in different measures, that enables comparisons, allows the use of input and output vectors and requires lesser degrees of freedom. 
Tabatabaei and Bazrkar (2019), on observe the criticized DEA flexibility in the selection of input and output weights and its self-evaluation nature, to be counteract by using the cross-efficiency model. Double Perspective Data Envelopment Analysis on incorporate the statistical analysis improve the assessment process to opt for a unique model according to the assumptions of the Best Unbiased Estimator (BUE) (Novaes et al., 2018).

The bibliographical review carried out culminates in the application of a Systematic Analysis adopted by Valmorbida and Ensslin (2016), refer to Table 1. This analysis portraits the main gaps of the actual Performance Measurement System operating in CAIXA and propose the desirable attributions that the designed PMM in this paper will improve the management of performance.

Complementary, Camioto et al. (2017) interpret the essential propose of this paper when they define and assess the slacks between the current performance and the performance target of each sector were compared to each variable analyzed. The slack expresses what degree the current performance of the DMU Decision Making Unit (named RMO in this paper) is distant in each variable, its ideal performance, which can be symbolized by a virtual DMU or RMO that is at the efficient frontier (also called a benchmark). This ideal performance was considered a target for the inefficient DMUs on PerformerDEA application at the modeling section (Novaes et al., 2012).

An analysis was established to verifies current CAIXA PMS capacity of performance management against the following advanced variables: design, implementation or use of performance measurement systems (PMS); Nudurupati et al. (2011) describe the concern with what to measure and how to structure PMS, i.e. the PMS life cycle, which then means determining how to design, implement and use PMS.

To determine these variables, some of the articles of the bibliography review, after the full reading of the content, classify this according to the theoretical affiliation of the researchers in drawing; design, implementation and use.

Complementary, Melnyk et al. (2014) proposed to this the verification of which variables are components of a Performance Measurement and Management (PMM), in: responsible for encompassing the process for goal setting (metric set development) and collection, analysis and interpretation of identified performance; and which assesses actual and desired results, and determines critical points for incorporating corrective actions and identifying performance gaps.

\section{METHODOLOGY}

In order to attend the introductory prescriptions on management and measuring theory, the work group selected the Data Envelopment Analysis (DEA) methodology. It consists essentially in determining the relative efficiency of each corporate unit over its comparable counterparts. The technique establishes a parameter of efficiency a benchmark function formed statistically by the results of performance achieved by the units with the best performance. The analysis is done through non-parametric approximations, that is, a priori equation is not defined that establishes the parameters to be considered. However, through Mathematical Programming, the relationship between the various units evaluated and the statistical data collected is defined, an objective function is defined for output maximization or input minimization for each unit evaluated, which is restricted to the inequalities established according to the statistical relationship by the relationship between the data collected. Empirical benchmark production function is statistically formed by efficient DMU - Decision-Making Units.

With reference to the literature review, is designed a dynamic organizational Performance measurement and managerial system (PMM) constituted by a data mining algorithm interfaced with PerformerDEA software. This PMM framework, will be permit that the measurement and the management of performance will be periodical testified, allowing to the organization has a continuous self-learning system with flexibility to be adapted to variations of market and strategies of the banking institution. A Data mining process was performed to capture, summarize and combine data of corporate digital core promoting the integration of IT platforms (Kholghi and Keyvanpour, 2011).

The PerformerDEA software has the capability of assessment the performance of managerial units in four different configurations. Each configuration is defined from specific objectives and consequently of the market environment of the organization (e.g. reduce labor working hours for a specific unit). It is based on the classic methods of Data Envelopment Analysis, developed for performance evaluation carried out in a so-called "input-oriented" or "output-oriented" performance developed by Charnes et al. (1978), called CCR, which uses constant-scale called CRS, Constant Returns of Scale (Coelli et al., 2005), and the Banker et al. (1984) method, called the BCC or VRS, which uses Variable Returns of Scale (Coelli et al., 2005).

The essential feature of the DEA method is the computation of multiple outputs by multiple input for each organizational unit, reduced to a single overall efficiency measure, identifying the causes and estimating the quantities of identified inefficiencies (Camioto et al., 2017). 
The essential feature of the CRS method is the computation of multiple outputs by multiple input for each organizational unit, reduced to a single overall efficiency measure, identifying the causes and estimating the quantities of identified inefficiencies (Camioto et al., 2017). From the performance evaluation of $\mathrm{n}$ observed units, with $\mathrm{m}$ input and outputs, the DEA model determines a subset of $k$ efficient units. These units are considered benchmark units and define the segments of the envelope surface, through the envelope shape in the DEA CCR or BCC models. The subset contained by the envelope and not belonging to this surface, is formed by $n-k$ non efficient units.

The computation of the efficiency, for each observed unit, requires the solution of a Linear Programming Problem. The classical formulation of the DEA CCR and BCC methods, according to the output-oriented dual models of the multipliers and envelope, is shown in Table 2 . In the multipliers model, the optimal values of the decision variables: $\mu, \pi$ and ${ }^{*}$ are the surface hyperplane parameters defined by the inequality constraint (3) such that the observed unit "O" achieves the highest possible efficiency

Table 2 - Output-oriented CRS and VRS models

\begin{tabular}{|c|}
\hline Multipliers (Primal) \\
\hline $\operatorname{Min} L_{0}=\sum_{i=1}^{m} \varpi_{i} x_{i 0}+u_{0}^{*}(1)$ \\
\hline Subjectto $\sum_{r=1}^{s} \mu_{r=} y_{r 0}=1(2)$ \\
\hline$-\sum_{r=1}^{s} \mu_{r} y_{r j}+\sum_{i=1}^{m} \varpi_{i} x_{i j}+u_{0}^{*} \geq 0 j=1, \ldots, n(3)$ \\
\hline$\mu_{r} \geq \varepsilon, r=1, \ldots \ldots, s, \varpi_{i} \geq \varepsilon i=1, \ldots ., m(4)$ \\
\hline$\varpi_{i}, \mu_{r}>0, \forall i, r(5)$ \\
\hline ForCCR $: u_{0}^{*}=0 \quad$ ForBCC $: u_{0}^{*}$ unconstrained $(6)$ \\
\hline Envelopment (Dual) \\
\hline $\operatorname{MaxH}_{S}=h_{S}+\varepsilon \sum_{y=1}^{s} s_{y}^{+}+\varepsilon \sum_{x=1}^{r} s_{x}^{-}(7)$ \\
\hline Subjecttoh $_{S} y_{r 0}-\sum_{j=1}^{n} \lambda_{j} y_{r j}+s_{r}^{+}=0, r=1, \ldots \ldots, s(8)$ \\
\hline$-x_{i 0}+\sum_{j=1}^{n} \lambda_{J} x_{i j}+s_{i}^{-}=0, i=1, \ldots \ldots, m(9)$ \\
\hline$\lambda_{j}, s_{r}^{+}, s_{i}^{-} \geq 0, \forall k, j, i(10)$ \\
\hline ForBCC $: \sum_{j=1}^{n} \lambda_{j}=1(11)$ \\
\hline
\end{tabular}

in the function objective (1). Efficiency can be defined as the minimum linear combination of inputs (1) from the linear combination of outputs (2).

The non-Archimedean constraint of the multipliers (4) may be the substitution of the classical constraint of the multipliers (5), where $\varepsilon$ is an infinitesimal (non-Archimedean) quantity.

According to the envelope form, the problem consists in the maximization of the objective function (7) applied on the variable $h_{s^{\prime}}$ subject to the restrictions of (8) to (11). According to the assumptions of the BCC method, the linear combination will be subject to a convexity constraint (11), which is not considered in the CCR model. The inclusion of this last constraint in the BCC model corresponds to the dual unrestricted variable (6) in the multiplier mode.

Analogously, Table 3 shows both dual CCR and input-oriented BCC models of multipliers and envelope. The variables and constraints are similar to the output-oriented model (Table 2), the main difference is that

Table 3 - Input-oriented CRS and VRS models

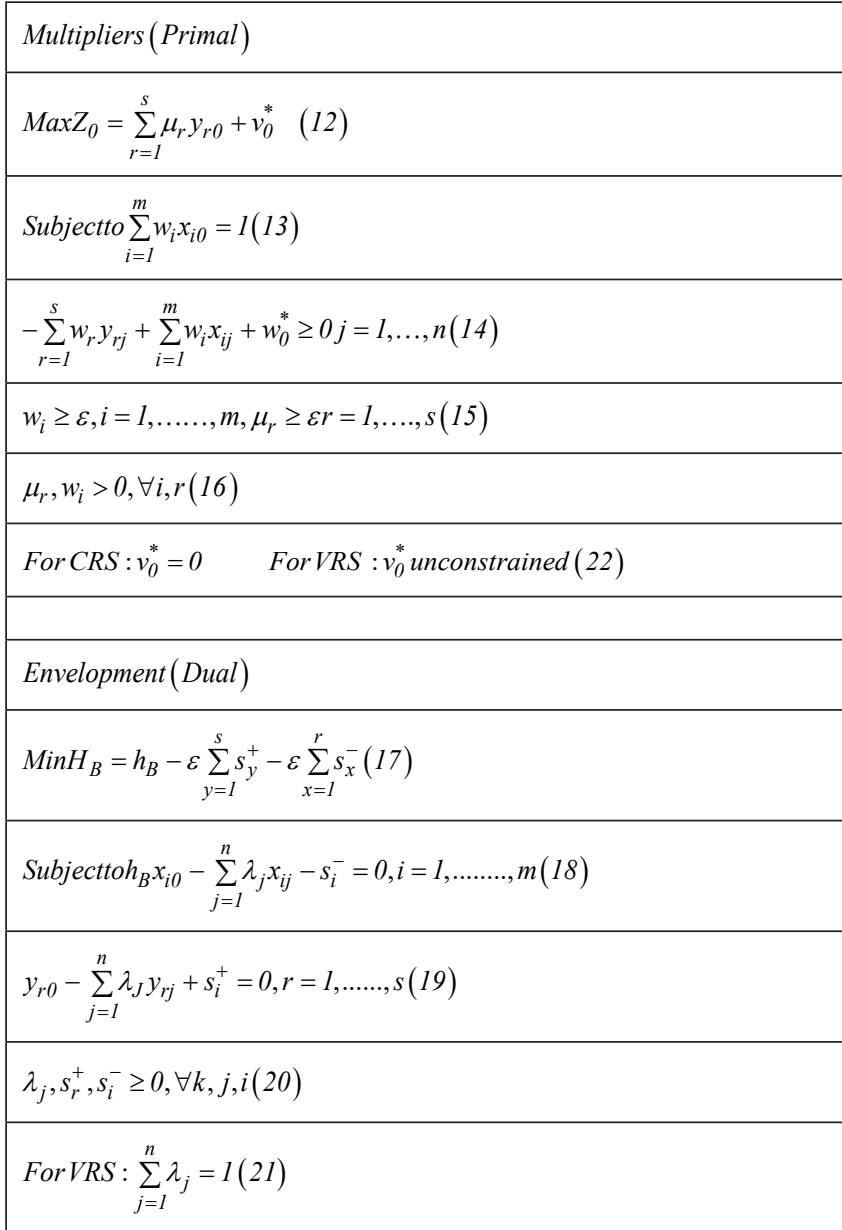


the multipliers model, the objective function maximizes the linear combination of the outputs of the observed units (12), normalizing the constraint of inputs (13).

In the envelope model the main difference lies in the minimization of the objective function corresponding to variable $h_{B}$ and its multiplication by the input of the evaluated unit at first term of the inequation (18).

\section{BACKGROUND}

The Brazilian Federal Saving Bank - CAIXA ECONÔMICA FEDERAL - is the major economic agent in the segment of mortgage credit in Brazil, with a market-share of $67.2 \%$, launching $\mathrm{R} \$ 384.2$ billion in 2015 . The mortgage investment represents 9\% of Gross Domestic Product, it is expected a high gradual increment of these participation. The Securitization Program launch these year (2019) opens a new perspective of financial support.

The mortgage credit is about $60 \%$ of CAIXA investment portfolio, that offers through its Housing Loan Credit network, refer to Figure 1, with about thirty-five thousand branches and representative offices located at metropolitan centers until remote villages in the country.

Each RMO is the regional headquarter of real estate analysis and valuation at the Housing Loan Credit network that support the superintendence offices, branches and its representative offices on each loan agreement, refer to Figure 1. RMO staff has the attribution of analyze of the feasibility and monitor investments portfolio of the bank in housing or commercial developments to be viable Mortgage Loan contracts with effective assets of guarantee, verifying if they the compliance with legal postures of city hall urban and housing department and environmental impacts conditions. This activities are supported by local inspection, done to verify property characteristics and the physical conditions. In order to be able to carry out these duties each RMO has a mixture of engineers, architects and social technics, with administrative staff who carry out clearly defined duties.

Every month an inspection is done to liberate the month parcel of the financial of a housing enterprise construction. Too, for each housing loan agreement, it is required an inspection for assess property value and verify its physical conditions. To viable these enormous challenge of covering whole country, the RMO with account of more than 5 thousand engineering or architectural firms to complementary implement its activities. The Country is subdivided into six regions, the seventy-two RMO are distributed into these regions: Region North with 9 RMOs; Region Northeast with 16 RMOs; Region Central West with 6 RMOs; Region Southeast with 12 RMOs; Region of São Paulo with 13 RMOs, and; Region South with 16 RMOs, refer Figure 2.

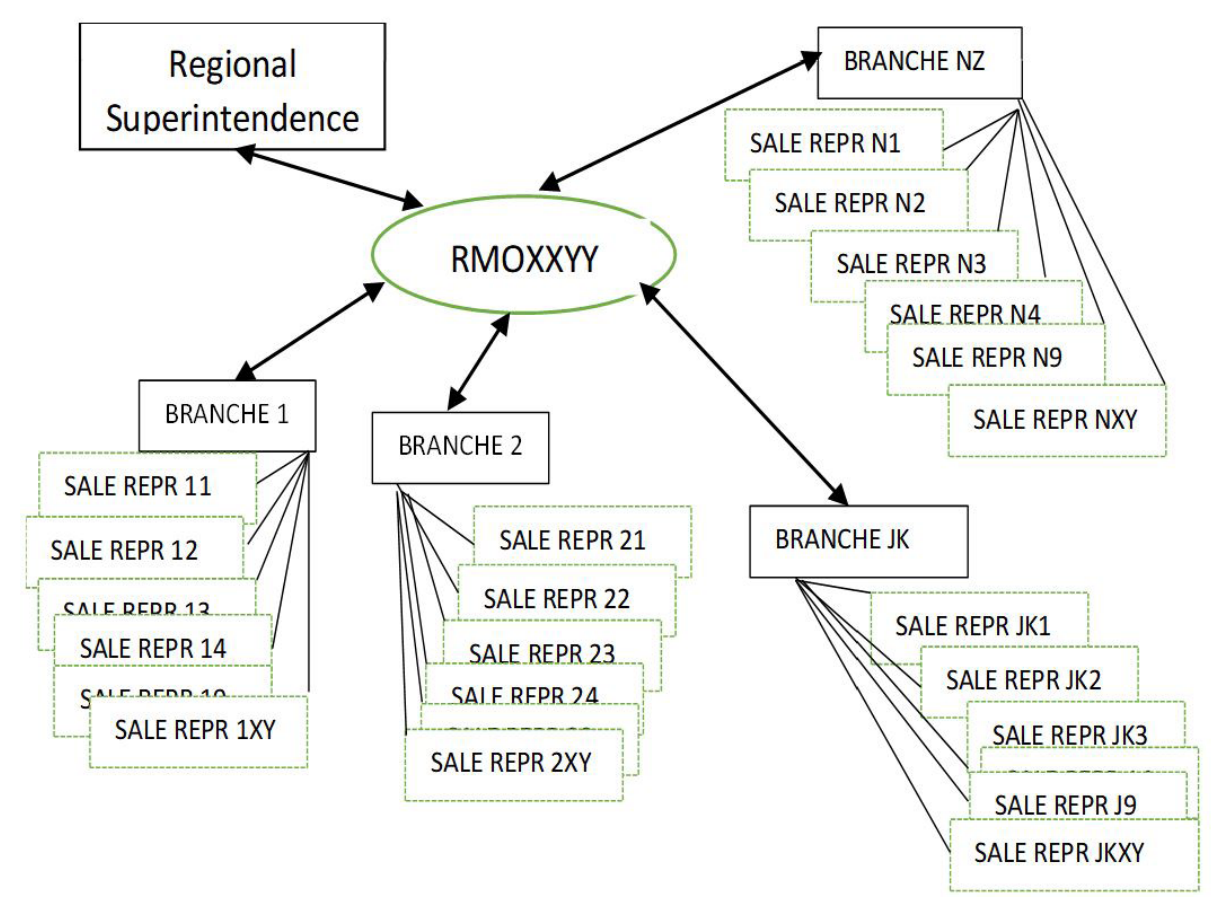

Figure 1- Housing Loan Credit network 


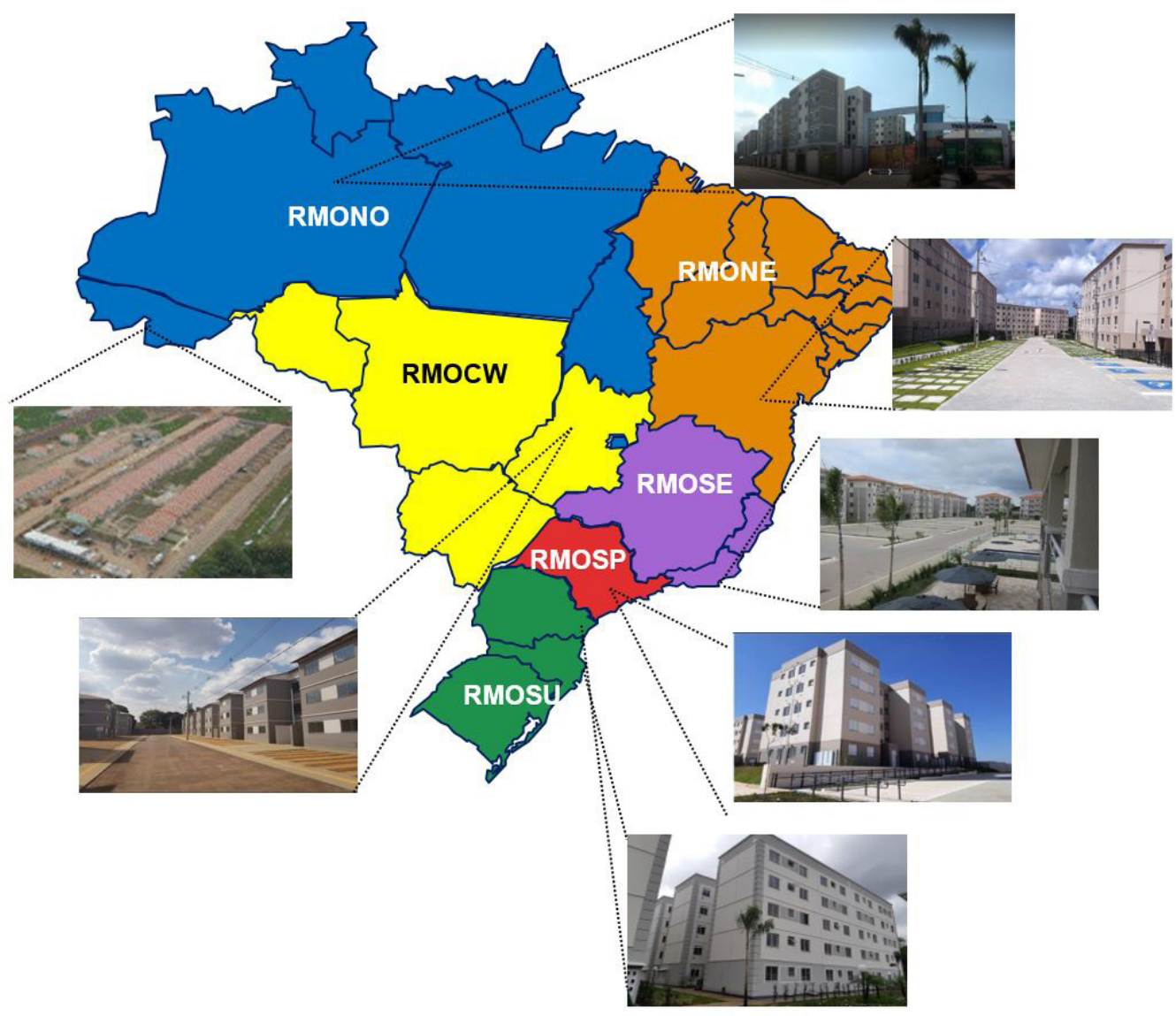

Figure 2 - Scope of Macro Regions Managerial Segment and Housing Developments MCMV

All internal process begins with some requisition that may be to analyze the viable of a new enterprise housing project until a single property valuation. When a process is registered, a case is opened which remains open until either the RMO activity is concluded.

Current, a management system is applied by CAIXA to establish the target to each RMO, it considers the effectiveness of the RMO in observe the monthly proposed targets.

This study case intends demonstrates a new management perspective to the Institution, that accounts the results and the costs, i.e., the management efficiency at the use of resource in reach its targets. How the proposed PMM system improves performance management and measurement processes, demonstrating how a best practice can be established by the management experience of the units of own institution. Then, a primordial utility in the way of performance assessment to the perpetuation of the Institution in a market environment that keeps getting more and more competitive.

\section{MODELING PROCEDURE}

The primordial procedure concerns to understand who are the RMO's customers and its demographics, on the objective of modeling range if the whole region or part of it and select the outputs and inputs variables. At the network described, refer to Figure 1, the direct customers are the representative organizational offices and branches, but the final customers are the physical persons and juridical persons regarded at a habitational loan agreement. In the context of the RMO production at the Housing Loan Credit network, the variables are the quantities of outputs to be produced as well as the quantity of inputs used. The best way with account of the results of RMOs outputs is basis with the final customers outputs list in the perspective of two dimension - the Client and Financial dimensions, refer to section 5.1 - item $2^{\circ}$ - Appropriation of representative variables of Inputs and Outputs.

The first dimension is the Client dimension, defined from the outputs achieved to the final clients, based on quantities of Housing Units or Housing Enterprise Global value delivered. 
The second dimension is the Financial dimension, defined from the outputs achieved from the liquid income of each RMO.

To establish the RMO's modeling range and outputs and inputs variables that explain the consumer behavior of Caixa loan agreement portfolio, had analyzed of the key of consumer demographics, their income level or cultural influences. The current of effectiveness management process ranks the units at a unique system that consider whole country to award the managers of the most effectiveness units. The comparable units are segmented for each organizational area related to each Vice Presidency. These prerogative and the fact of PMM, initially, being a complementary performance management and measurement system, are the scope regarded to decision variables choice.

The fact is, the consideration of unique modeling to the whole country, has a market and technical basis to be consider. The region covered of each RMO has similar contrasts, since the North region until the South region. Part of customers lives on urban regions with concentrate density of land occupations and with integrated urban infrastructure. In the oppose way, others live in sparse concentration region, similar to rural areas or live on the limits of the urban centers suffering from the irregular presence of services, equipment and urban infrastructure.

The influence of differences of local or neighborhood infrastructure characteristics is factored into the hedonic model, which was used in estimating the relative influence of different variables to real estate assessment, since for a single house until a housing developments on the basis of sampling of sales of similar real estate, one of the RMO staff activities that support the housing agreement.

Consequently, by the law of supply and demand, we concluded that the real estate value to a loan agreement, is been adequate with the customer's income on contracting a specific product of credit between to the several options by the Caixa habitational credit portfolio, that are offered in the whole country. This aspect, particularly, homogenies the regionals differences of customer's income that is correlated with some specific regional product of Caixa Housing Loan Credit.

Another question to consider, is that the portfolio of housing developments has a building patterns been applied in all regions of the country, refer to Figure 2. The portfolio of habitational loan credit has correlation with the building pattern and typology adopted in whole country. The difference between regional construction cost is correlated with regional housing's difference of market value, e.g., the building enterprises showed at Figure 2, for each macro region, are related with the loan agreement prescribed to customer's incomes about 1.5 salary minimum.

Seeing the pictures of housing developments, on Figure 2, is perceived the existence of similar patterns and building typology, that's enabled to conclude for the inexistence of cultural regional differences to influence the consumer behavior, on buying these habitational units. On the aspect of the RMOs outputs represented by the selling habitational units in value or quantity, the first conclusion is that they do not suffer influence of different cultural characteristics between regions.

From the above described aspect is performed the segmentation of the macro regions that the RMOs are grouped, similar with is observed at the organizational current effectiveness model applied to rank the RMOs, refer to Figure 2. Another aspect we can conclude, that is perceived on considering part of outputs to RMO represented by the quantity or total value of selling habitational units with housing loan agreement ranged by customer regional income, one or other, are the output variable that homogenizes the regionals differences between regional customers cultural aspects or incomes.

It was observed at the high correlation (green color, refer to Figure 3) of the outputs represented by quantities or total values of selling habitational units (UH RG 1 until UH RG 3; UHOUT; Revenue; Contribution Margin and PSR) with the inputs represented for exogenous variables to explain regional geographic differences (Total Housing Deficit, Urban and Population Urban).

The modeling proceed was subdivided into two phases - Diagnosis and Treatment. The first is the diagnosis phase that represents the measuring process, where was testified by the group of experts if the PMM shall use CRS or VRS model. The second phase was demonstrated the treatment proceeds that represents the managing process to be implement to all RMO, from the PMM model approved on the phase 1.

Daily, expenditures based on staff, fixed and variable cost and the results of products portfolio of investments are accountable by each RMO. All resources are contemplated at the Annual Balance of the Banking Institution (Valle, 2019). In this paper, data from the Financial Institution under study have undergone scale changes in order to preserve their confidentiality. 
Ad... APS GE... PR... P... DE... DEF... DEF... PO... PO... FX... FX... FX1,5a3... FX2... FX3... FOR... UH... UHF... UHFX1,5 UHF... UHFX3 UHF0... REC... RPS MA...

\begin{tabular}{|c|c|c|c|c|c|c|c|c|c|c|c|c|c|c|c|c|c|c|c|c|c|c|}
\hline & & & & 65,91 & 67,40 & 22,18 & 69,04 & & $30,97 \quad 31,49$ & 54,82 & 54,00 & 31,58 & 61,66 & 51,41 & 57,10 & 36,36 & 56,96 & 38,67 & 58,37 & 66,56 & 67,73 & 61,44 \\
\hline APS & 4,17100 & 56,45 & $64,6971,39$ & 70,61 & 71,33 & 26,20 & 71,34 & 29,2 & 624,12 & & 4123 & 32,41 & 5720 & 51,55 & 53,57 & 31,56 & 52,38 & 41,33 & 6426 & 58,54 & 237 & \\
\hline Manager & $77,00 \quad 56,45$ & 00,1 & $74,1183,45$ & 64,79 & 66,52 & 21,10 & 65,88 & & $35,51 \quad 29,12$ & 47,85 & 47,57 & 25,23 & 62,88 & 51,27 & 52,20 & 31,43 & 53,66 & 31,94 & 61,83 & 68,37 & 67,37 & 6249 \\
\hline of UAE & $80,6264,69$ & 74,11 & $100,0093,69$ & 78,14 & 84,86 & 12,67 & 87,45 & 14 & $33,66 \quad 37,01$ & 61,46 & 58,79 & 40,65 & 73,84 & 54,11 & 69,96 & 42,63 & 69,56 & 49,48 & 78,17 & 86,54 & 86,73 & \\
\hline & $95,5671,39$ & 83,45 & & 76,63 & 80,40 & 20,20 & 82,23 & & $35,67 \quad 35,48$ & 60,81 & 59,15 & 37,56 & 71,95 & 56,74 & 66 & 41,02 & 66,38 & 45,97 & 72,30 & 80,01 & 82 & \\
\hline & $65,9170,61$ & 64,79 & $78,1476,631$ & $100 \ldots$ & 95,16 & 53,24 & 89,15 & 44,24 & $62,20 \quad 23,36$ & 50,30 & 47,62 & 42,92 & 62,64 & 83,52 & 66, & 31,08 & 66,59 & 52,94 & 75,70 & 74,52 & 78,07 & \\
\hline t1) & $67,40 \quad 71,33$ & 66,52 & $84,8680,40$ & 95,16 & 100,00 & 24,65 & 97,65 & 20,15 & $41,64 \quad 25,95$ & 59,63 & 56,51 & 52,88 & 72,05 & 69,67 & 76,36 & 32,49 & 76,04 & 63,79 & 84,82 & 88,54 & 91,29 & \\
\hline IRB & $22,18 \quad 26,20$ & 21,10 & $12,6720,20$ & 53,24 & 24,65 & 100,00 & 12,17 & 84,01 & $81,47 \quad 2,18$ & & & & & 71,48 & 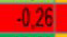 & 8.51 & & 8,18 & 5,09 & $-8,86$ & $0,2$. & \\
\hline Def RUR & $69,04 \quad 71,34$ & 65,88 & $87,4582,23$ & 89,15 & 97,65 & 12,17 & 100,00 & & $29,26 \quad 30,59$ & 66,07 & 63,01 & 55,04 & 74,29 & 57,87 & 80,59 & 38,40 & 79,94 & 65,30 & 85,51 & 92,70 & 95,00 & \\
\hline POPURB & 29,25 & 17.74 & 14,46 & 44,24 & 20,15 & 84,01 & 12,63 & 100,00 & $\begin{array}{lll}72,81 & -0,36\end{array}$ & $-11,08$ & $-9,74$ & -18,17 & & 57,07 & $-9,70$ & $-1,06$ & $.7,58$ & $.16,56$ & 6.47 & $-12,01$ & -6.98 & \\
\hline POPRUR & $30,97 \quad 38,96$ & 35,51 & $33,6635,67$ & 62,20 & 41,64 & 81,47 & 29,26 & 72,811 & $100,00 \quad 2,79$ & 0.41 & 0,61 & $-2,93$ & 15,4 & 80,13 & 9,44 & 7.21 & 10,76 & 1,52 & 23,39 & 9,84 & 13,56 & \\
\hline RANG1E & $31,49 \quad 24,12$ & 29,12 & $37,0135,48$ & 23,36 & 25,95 & 2 & 30,59 & $-0,36$ & $2,79100,00$ & 59,05 & 41,95 & 17.6 & 33,82 & 14,16 & 40,03 & 92,64 & 29,30 & 10,5 & 33,16 & 38,83 & 32,32 & \\
\hline NGG1,5 & $54,82 \quad 43,61$ & 47,85 & 61,46 & 50,30 & 59,63 & $-5,63$ & 66,07 & $-11,08$ & 59,05 & 100,00 & 96,11 & 66,09 & 64,59 & 24,09 & 91,11 & 62,67 & 89,10 & 63,76 & 57,85 & 73,42 & 73,30 & 18,32 \\
\hline & $54,00 \quad 41,23$ & 47,57 & 58, & 47,62 & 56,51 & $.5,49$ & 63,01 & $-9,74$ & $0,6 1 \longdiv { 4 1 , 9 5 }$ & 96,11 & 100,00 & 53,96 & 61,09 & 22,41 & 86, & 45,18 & 90 & 53,99 & 50,41 & 70,35 & 71,65 & 75 \\
\hline $\mathrm{R} 1,5 / 3 \mathrm{E}$ & $31,58 \quad 32,41$ & 25,23 & $40,6537,56$ & 42,92 & 52,88 & 10.31 & 55,04 & $\begin{array}{c}.18,17 \\
\end{array}$ & .29 & 66,09 & 53,96 & 100,00 & 49,41 & & 79,66 & 30,96 & 69,94 & 96,79 & 56,71 & 54,79 & 56,97 & 59.9 \\
\hline UHRG1 & $61,66 \quad 57,20$ & 62,88 & 73,84 & 62,64 & 72,05 & .0 .92 & 74,29 & 2,65 & $15,44 \quad 33,82$ & 64,59 & 61,09 & 49,41 & 100,1 & 39,41 & 69,67 & 36,65 & 67,83 & 57,78 & 89,69 & 77,01 & 78,29 & 15, \\
\hline UG1,5/3 & $51,41,51,55$ & 51,27 & & 83,52 & 69,67 & 71,48 & 57,87 & 57,07 & 80,13 & 24,09 & 22,41 & & 39,41 & 100,00 & 36,46 & & 36,93 & 25,74 & 48,96 & 41,21 & 44,09 & 42,40 \\
\hline UHG1,5 & $\begin{array}{llll}57,10 & 53,57\end{array}$ & 52,20 & $69,9666,51$ & 66,62 & 76,36 & -0.26 & 80,59 & $-9,70$ & $9,4440,03$ & 91,11 & 86,34 & 79,66 & 69,67 & 36,46 & 100,00 & 52,32 & 97,61 & 82,41 & 72,60 & 83,81 & 84,68 & \\
\hline UHRG2 & $36,36 \quad 31,56$ & 31,43 & $42,6341,02$ & 31,08 & 32,49 & 8,51 & 38,40 & $-1,06$ & $7,2192,64$ & 62,67 & 45,18 & 30,96 & 36,65 & & 52,32 & 100,00 & 39,93 & 24,16 & 39,14 & 43,45 & 37,86 & 41, \\
\hline UHRG3 & $56,96 \quad 52,38$ & 53 & 69,56 & 66,59 & 76,04 & 0.53 & 79,94 & $-7,58$ & $10,76 \quad 29,30$ & 89, & 90,00 & 69,94 & 67,83 & 36,93 & 97, & 39,93 & 100,00 & 74,29 & 68,39 & 83,62 & 85,22 & \\
\hline U & $38,67 \quad 41,33$ & 31,94 & $49,4845,97$ & 52,94 & 63,79 & $-8,78$ & 65,30 & 16,56 & 100 & 63,76 & 53,99 & 96,79 & 57,78 & 25,74 & 82 & 24,16 & 74,29 & 100,00 & 66,41 & 63,92 & 66,77 & \\
\hline & $58,37 \quad 64,26$ & 61,83 & $78,1772,30$ & 75,70 & 84,82 & 5,09 & 85,51 & 6,47 & $23,39 \quad 33,16$ & 57,85 & 50,41 & 56,71 & 89,65 & 48,96 & 72,60 & 39,14 & 68,39 & 66,41 & 100,00 & 83,19 & 84,54 & 79,3 \\
\hline REVENU & $66,56 \quad 58,54$ & 68,37 & $86,5480,01$ & 74,52 & 88,54 & -8.86 & 92,70 & 12,01 & $9,84 \quad 38,83$ & 73,42 & 70,35 & 54,79 & 77,01 & 41,21 & 83 & 43,45 & 83,62 & 63,92 & 83,19 & 100,00 & $98,73^{-}$ & \\
\hline PS & $67,73 \quad 62,37$ & 67,37 & $86,7380,82$ & 78,07 & 91,29 & $.5,25$ & 95,00 & $-6,98$ & $\begin{array}{ll}13,56 & 32,32\end{array}$ & 73,30 & 71,65 & 56,97 & 78,29 & 44,09 & 84. & 37,86 & 85,22 & 66,77 & 84,54 & & 100,00 & \\
\hline CONTMR & $61,44 \quad 54,81$ & 62,49 & $81,5474,53$ & 72,82 & 86,88 & $.9,68$ & 89,85 & -14.55 & $10,50 \quad 38,03$ & 78,32 & 75,78 & 59,90 & 75,07 & 42,40 & 86,65 & 41,20 & 86,80 & 67,73 & 79,38 & 97,01 & 97,0 & \\
\hline
\end{tabular}

WEAK

MEDIUM

HIGH

Figure 3 - Correlation Analysis of inputs and outputs on Client \& Financial Dimensions

\subsection{Phase 1 - Diagnosis}

At the diagnosis phase is simulated several models with different input packages and output sets grasped of organizational database. At the end of this phase, is elected final PMM model testified by the empirical expectative of the group of experts and selected to be used to measure the ranking efficiency on panels data of the years 2015, 2016 and 2017, and used at the second phase, the Treatment phase.

Figure 2 shows the map of the 6 Regions of coverage related to the 72 Regional Managerial Offices.

The Diagnosis of RMO performance accomplished the following sequence:

$1^{\circ}$ - Selection and definition of the observed units; $2^{\circ}$ - Appropriation of representative variables of Inputs and Outputs; $3^{\circ}$ - Analysis of Correlation of the eligible Inputs and Outputs; $4^{\circ}$ Simulation and selection of basket of input and output to PMM MODEL; 5 - Modeling Economies of Scale to define PMM MODEL, and; 6으- Conclusion.

\section{$1^{\circ}$. Selection and definition of the observed units.}

The set of units to be evaluated is defined according to the criterion that allows to find productivity differences, coming from the management of each unit, observing the follow conditions: carry out comparable tasks and obligations with the same technology and operational conditions, aiming to achieve similar results or objectives observed with a significant variation of economies of scale, under a workforce conditions and environment that are not equal.

$2^{\circ}$. Appropriation of representative of Inputs and Outputs variables.

One of the main challenges in our paper was define the variables set on considering its diversity and comprehensiveness of services and workforce of each output and input of each analyzed RMO Regional managerial office.

The Working Group grasped 25 eligible variables from three dimensions, that impacted the operational results of each RMO, i.e., the original self-outputs and self-inputs, considering active contracts. They are extracted by data mining algorithm of corporate core business related to the activities carried out in the corporate environment.

Client Dimension (outputs): Number of Housing/Enterprises in the Range 1; 1.5; 2 and 3; Number of Housing/Enterprises of OUT MCMV; UH Range 1- Quantity of Housing Units; UH Range 1.5, 2 and 3 - Quantity of housing units; UHOUT MCMV - Quantity of Housing Units; Global Total Sale Value (R \$); Valuation (SIOPI A412 + A414) - Accumulated 
for the last 12 months; Validation / Screening above 1 Million - Accumulated for the last 12 months.

Financial Dimension ( $R$ \$)(outputs) - (3 variables): Unit Revenue; Contribution Margin, PSR (Income from Service Provision).

Inputs Dimensions:

- Endogenous Inputs -

Administrative Cost ( $R$ \$); Personnel Cost (R \$); Amount of Personnel: LEP (Manager, UAE Professionals, Social, Operational / Administrative Technicians, Accredited Cost (R \$)).

However, other variables from regional characteristics of the corporate and market environment were analyzed and included in the model. In the prerogative of the need to incorporate homogenization factors of the data set analyzed. This is due to the fact that we are adopting a unique model for all regions of the country, which undoubtedly addresses a challenge to this case study. These variables were denominated as exogenous variables, that is, external to the corporate environment, but inherent to the marketing environment of each RMO - Regional Managerial Office.

\section{- Exogenous or environmental Inputs -}

On despite of regional differences influence daily staff work, the portfolio of the bank investment is the same for all RMO. The exogeneous or environmental variable defined and tested has the function to explain the RMO staff performance differences going on urban centers and countryside. From this criterion, the WG elected the exogeneous variables that observes aspects of differences between RMOs, to carry out staff work on analyze and control the investment portfolio of the bank applied on commercial, housing development, or still, a single house. Initially are prescript: Total Housing Deficit, Urban and Rural; Population Urban and Rural. The Tables 4 and 5 certified the power of explanation of the exogeneous variable selected, see next $4^{\circ}$ section.

\section{$3^{\circ}$. Analysis of Correlation eligible Inputs and Outputs.}

The correlation analysis between the component variables of the Inputs and Outputs set has the objective of verifying the existing behavior among the variables, in order to allow the selection and configuration of relevant and appropriate input and outputs for the evaluation of the relative efficiency between the units evaluated. Through the research carried out from the digital platform, the collection of inputs and related outputs was initially selected.

Clearly was achieved groups or families of variables, the colored green sets, with high correlation with each other. Upper left is the family of inputs and lower right is the family of outputs, refer to Figure 3.

At this stage, the Working Group was prepared to testify and choose the PMM model to be considered for performance management. Through the simulation of a range of models generated from different packages of inputs and sets of outputs by Digital Corporate Database Platform integrated with PerformerDEA (2019) analytical software allows the establishment of benchmarking targets, based on the results achieved by the best performance units, based on the resources used, generating a ranking of efficient and inefficient units.

Each model resulting from combinations of the baskets of inputs and outputs could be analyzed and evaluated by the experts involved.

$4^{\circ}$. Simulation and selection of basket of input and output to PMM MODEL.

DEA has a limitation of the number of inputs and outputs used in relation of the number of units in assessment. In aggregating inputs with high correlation, each other, promotes a better procedure to measurement efficiency, turning the PMM model in alignment with the expectation of its functionality, the same result occurs with outputs composed.

According to the criteria defined above, all inputs variables of cost were aggregated at an input variable named of Total Cost referred to the fixed cost variables of each RMO. The output variable chosen to represent the financial dimension was Contribution Margin by verifying it high correlation with the Inputs variables of Cost.

The variable input SIPLO was grasped by data mining algorithm. SIPLO represents the variable cost of each RMO, relative to external works done by credential enterprises and staff on supervising external RMO activities.

To homogenize the data analyzed according to the variation of the logistic of external work carried out and of the market handicap of RMO, we aggregated urban and rural deficit per RMO coverage area $(\mathrm{km} 2)$. The input - Deficit hab. / Area - is representative of this logistic differentiation of external RMO activities inherent to the process of analysis and monitoring of housing investments and of a market handicap differencing the regions. Especially, among the staffs located in large urban centers with others located 
Table 4 - Relation of reference RMOs for each inefficient RMO - 2017

\begin{tabular}{|c|c|c|c|c|c|c|c|c|c|c|}
\hline \multirow{2}{*}{$\begin{array}{l}\text { Inefficient } \\
\text { RMO }\end{array}$} & \multirow{2}{*}{$\begin{array}{c}\text { Perfor } \\
\text { mance \% }\end{array}$} & \multirow{2}{*}{\begin{tabular}{|c} 
Efficient \\
Reference \\
RMO \\
\end{tabular}} & & & & & & \multicolumn{2}{|c|}{ REGION } & \multirow{2}{*}{$\begin{array}{l}\text { Same } \\
\text { Scale }\end{array}$} \\
\hline & & & & & & & & Same & Bordering & \\
\hline RMOSU12 & 99,56 & RMOSE10 & & & & & & & & OK \\
\hline RMOCW05 & 99,54 & RMONE02 & & & & & & & OK & OK \\
\hline RMOSU07 & 99,16 & RMOSE06 & RMONO03 & RMONO04 & RMONE15 & & & & & OK \\
\hline RMOSU04 & 99 & RMOCW02 & RMONO04 & & & & & & OK & OK \\
\hline RMONE09 & 98,98 & RMONE11 & RMOSE06 & & & & & OK & OK & OK \\
\hline RMOCW03 & 98,75 & RMOCW04 & RMONO03 & RMOSE14 & RMOSE10 & & & OK & OK & OK \\
\hline RMONO06 & 98,45 & RMONO03 & RMONO04 & RMOCW02 & & & & OK & OK & OK \\
\hline RMOSP03 & 98,18 & RMOSPO2 & RMOSP01 & RMOCW01 & RMOSE09 & RMOSE13 & RMOCW01 & OK & $\mathrm{OK}$ & OK \\
\hline RMONE15 & 98,02 & RMONO03 & RMOCW01 & RMOSE06 & & & & & OK & \\
\hline RMOSU06 & 98 & RMOSE06 & RMOCW07 & & & & & & OK & OK \\
\hline RMOSU08 & 98 & RMOSE06 & RMOCW07 & & & & & & OK & OK \\
\hline RMONE06 & 98 & MOSD06 & RMOCW07 & & & & & & OK & OK \\
\hline RMOSU15 & 97,55 & RMOCW01 & RMOCW07 & RMOSE06 & RMOCW04 & RMOSP10 & & & OK & OK \\
\hline RMOSP13 & 97,25 & RMOSE02 & RMOSE06 & RMOSE09 & RMOSE13 & RMONE03 & & & OK & OK \\
\hline RMOSU02 & 97,02 & RMOSE02 & RMOCW01 & RMONE14 & & & & & OK & OK \\
\hline RMONE03 & 96,74 & RMOSE06 & RMOSE02 & RMOSE09 & & & & & OK & OK \\
\hline RMOSP08 & 96,17 & RMOSPO2 & RMOSP01 & RMOSE06 & RMOSE09 & RMOSE13 & RMOCW01 & OK & OK & OK \\
\hline RMONE01 & 96,04 & RMONE14 & RMOSE02 & RMOSP10 & & & & OK & OK & OK \\
\hline RMONO02 & 96,01 & RMONO03 & RMOCW02 & RMOCW04 & & & & OK & OK & OK \\
\hline RMOSU09 & 96 & RMOSE06 & RMOSP05 & RMONE10 & RMOCW07 & & & & OK & OK \\
\hline
\end{tabular}

Table 5 - Relation of reference RMOs for each inefficient RMO - 2017

\begin{tabular}{|c|c|c|c|c|c|c|c|c|c|c|}
\hline \multirow{2}{*}{$\begin{array}{l}\text { Inefficient } \\
\text { RMO }\end{array}$} & \multirow{2}{*}{$\begin{array}{c}\text { Perfor } \\
\text { mance \% }\end{array}$} & \multirow{2}{*}{\begin{tabular}{|c|} 
Efficient \\
Reference \\
RMO \\
\end{tabular}} & & & & & & \multicolumn{2}{|c|}{ REGION } & \multirow{2}{*}{$\begin{array}{l}\text { Same } \\
\text { Scale }\end{array}$} \\
\hline & & & & & & & & Same & Bordering & \\
\hline RMOSP07 & 95,2 & RMOSP05 & RMOSP10 & RMOCW01 & RMONE14 & & & OK & OK & OK \\
\hline RMOSP06 & 95,05 & RMOSP05 & RMOSP10 & RMOSE13 & RMOCW01 & RMONE14 & & OK & OK & OK \\
\hline RMONE05 & 94,9 & RMONE11 & RMOSE06 & RMOSE13 & & & & OK & OK & OK \\
\hline RMONE04 & 94,34 & RMOSE10 & RMOSP10 & & & & & & OK & \\
\hline RMOSU10 & 94 & RMOSP10 & RMOSU13 & RMONO04 & & & & OK & OK & OK \\
\hline RMOSU11 & 94 & RMOSU13 & RMONE14 & RMOSP05 & RMONO04 & RMOSP10 & RMOCW07 & OK & OK & OK \\
\hline RMOSE03 & 94 & RMOSU13 & RMOSP10 & RMONO04 & & & & & OK & OK \\
\hline RMONO08 & 92,69 & RMONO04 & RMONO03 & RMOCW02 & RMOSE10 & & & OK & OK & OK \\
\hline RMOSU16 & 92,25 & RMOCW01 & RMONE14 & RMOSE02 & RMONO04 & RMOSP01 & & & OK & OK \\
\hline RMOCW06 & 91,78 & RMONO04 & RMOSE10 & RMOSE13 & RMONE12 & & & & OK & OK \\
\hline RMONE08 & 91,04 & RMOSE06 & RMOSP10 & RMOCW01 & & & & & OK & OK \\
\hline RMONO05 & 87,14 & RMONO03 & RMOCW01 & RMOSE13 & RMOSE10 & & & OK & OK & OK \\
\hline RMONO01 & 87 & RMONO03 & RMOSP05 & RMOSP10 & & & & OK & & OK \\
\hline RMONE07 & 87 & RMOSE06 & RMOCW07 & & & & & & OK & OK \\
\hline RMOSE12 & 85,09 & RMOSE02 & RMOSE13 & RMONO04 & RMONE03 & & & OK & OK & OK \\
\hline RMONE13 & 85 & RMOSP10 & RMOCW07 & & & & & & OK & OK \\
\hline RMONE02 & 84,35 & RMOSE02 & RMOCW01 & RMOSP10 & & & & & OK & OK \\
\hline RMOSE07 & 82 & RMOSE06 & RMOCW07 & & & & & OK & OK & OK \\
\hline RMOSE11 & 79,31 & RMOSE02 & RMOSE06 & RMOSE09 & RMOSU01 & RMONO04 & & OK & & OK \\
\hline RMOSE08 & 79,22 & RMOSE02 & RMOSE13 & RMOSP05 & RMOSP10 & RMONE14 & & OK & $\mathrm{OK}$ & OK \\
\hline \multirow[t]{2}{*}{ RMONO07 } & 76,55 & RMONO04 & RMOSE10 & RMOSE14 & RMOCW02 & & & OK & $\mathrm{OK}$ & OK \\
\hline & & & & & \multicolumn{3}{|c|}{ TOTAL PERCENTAGE } & \multicolumn{2}{|c|}{$95,3 \%$} & $95,3 \%$ \\
\hline
\end{tabular}


in remote locations and difficult to access. This situation is trivial in the corporate environment. For instance, since there are staffs located in the Amazon region being compared with staffs located in the city of São Paulo.

The basket of input chosen to define the model as the most adherent to the expectation of the group of experts, is related to the following:

- Cost $(R \$) \rightarrow$ Annual personnel cost + Annual administrative cost + Annual accredited cost (source: SIPLO).

-SIPLO (Cost (R \$)) $\rightarrow$ Annual Cost of Daily, transportation and lodging of the RMO.

- Deficit hab / Area $\rightarrow$ Urban and rural housing deficit - base - 2010 census (source: João Pinheiro Fund) multiplied per 100 / RMO coverage area $(\mathrm{km} 2)$.

The set of outputs chosen to define the model as the most compliant to the expectation of the group of experts is related to the following:

-Contribution margin $(R \$) \rightarrow$ Annual sum of the revenues of the local agency linked to the Regional Offices related to physical persons and juridical persons of bank portfolio of housing and commercial investments products (source: SICRS).

-Non-Critical Venture $\rightarrow$ percentage of the numbers of Housing Units (HU) of non-critical ventures (except when invaded and with lawsuit which prevents continuation) in relation to the number of $\mathrm{HU}$ of contracted ventures in the last 3 years.

-Delivery Except Range $01 \rightarrow$ percentage of the numbers of HU of Housing Developments delivered, except MCMV Range 01 in relation to $\mathrm{HU}$ of Housing Developments, except MCMV Range 01 contracted in the period of 3 to 6 years.

To verify if the exogeneous or environmental variable elected - Deficit habitational /Area - homogenized the regional handicap. On comparing with usual variables, Municipal Human Development Index (MHDI) per States the correlation was $51 \%$ and with per capita income index was $65 \%$, demonstrating moderate correlation.

But significantly to consider a unique model to assessment all RMOs together, it was tested if the PMM model observed the regionality logistic condition explained by Deficit hab./ Area, refer to Tables 4 and 5 . At the level of $95,3 \%$, was observed that the model autonomously mapped out to each inefficient RMO, the RMOs efficient references was located at the same region or bordering. These observed results do Deficit hab./ Area credit the power of homogenize the differences of regionally staff external works of the RMOs. 5o - Modeling Economies of Scale to define PMM MODEL

On accounting the global percent performance between RMO efficient and inefficient, was verified that DEA VRS is more adherent with the Work Group expectation, the CRS model, $23.61 \%$ of the RMOs are efficient, while in the VRS model they are $40.28 \%$.

The simulated panel data of 2017 graph DEA CRS Output-Oiented with 2 inputs - Cost and SIPLO for 1 output - Contribution Margin, Figure 4, and graph DEA CRS Input-Oriented with 2 outputs - Contribution Margin and \%_N critical / Cost X Marginal Contribution for 1 input - Cost, Figure 5, demonstrate the potential from DEA efficiency analysis. The frontier developed is performed by the benchmark units.In the results of the efficiency ranking, Table 6 , is verified that percentage of RMO efficient on the VRS model has better distribution than CRS model between the Macro Regions, refer to Figure 2 (NO, CW, NE, SE, SP and SU).

Analyzing, the graphs of Figures 6 and 7 , on accounting the times of occurrences of inefficient RMO per efficient RMO, it is veriffied that the VRS model, refer to Figure 7, contemplates a best distribution of the number of occurrences, besides the increase in the numbers of reference RMO .

In Figure 6, the total of references RMO efficient is 15. The efficient RMOSE10 was been the greatest reference with 48 occurrences for inefficients RMO and RMOCW01 was reference for 31 inefficients RMO.

On the other hand, refer to Figure 7, the graph of VRS model totalize that are 27 references of RMO efficient. The efficient RMOSE06 was the greatest reference for 20 inefficient RMO and RMONO04 was reference of 13 inefficients

\section{6o - Conclusion of Diagnosis phase}

The overall view of the diagnosis phase required that the WG validate the use of output VRS PMM MODEL, refer to Table 6 and Figures 4,6 and 7 by PerformerDEA software on the treatment phase considering the basket of inputs and outputs formed by 3 inputs - Deficit hab $\times 1000$ /Area, Cost and SIPLO for 3 outputs - Contribution Margin, Pre not Critical and FORA.

PMM applying generated the first function of it design, that is the measurement functionality. At this characteristic, the Graph of Cross Section Variation of Macro-Regional Efficiency of 2015/2016/2017 - DEA VRS Output oriented permits to understand the regional efficiency distribution and variation, refer to Figure 8 . Table 7 and 8 gives detail of the efficiency of RMO into each macro-region from the years of 2015 to 2017. 


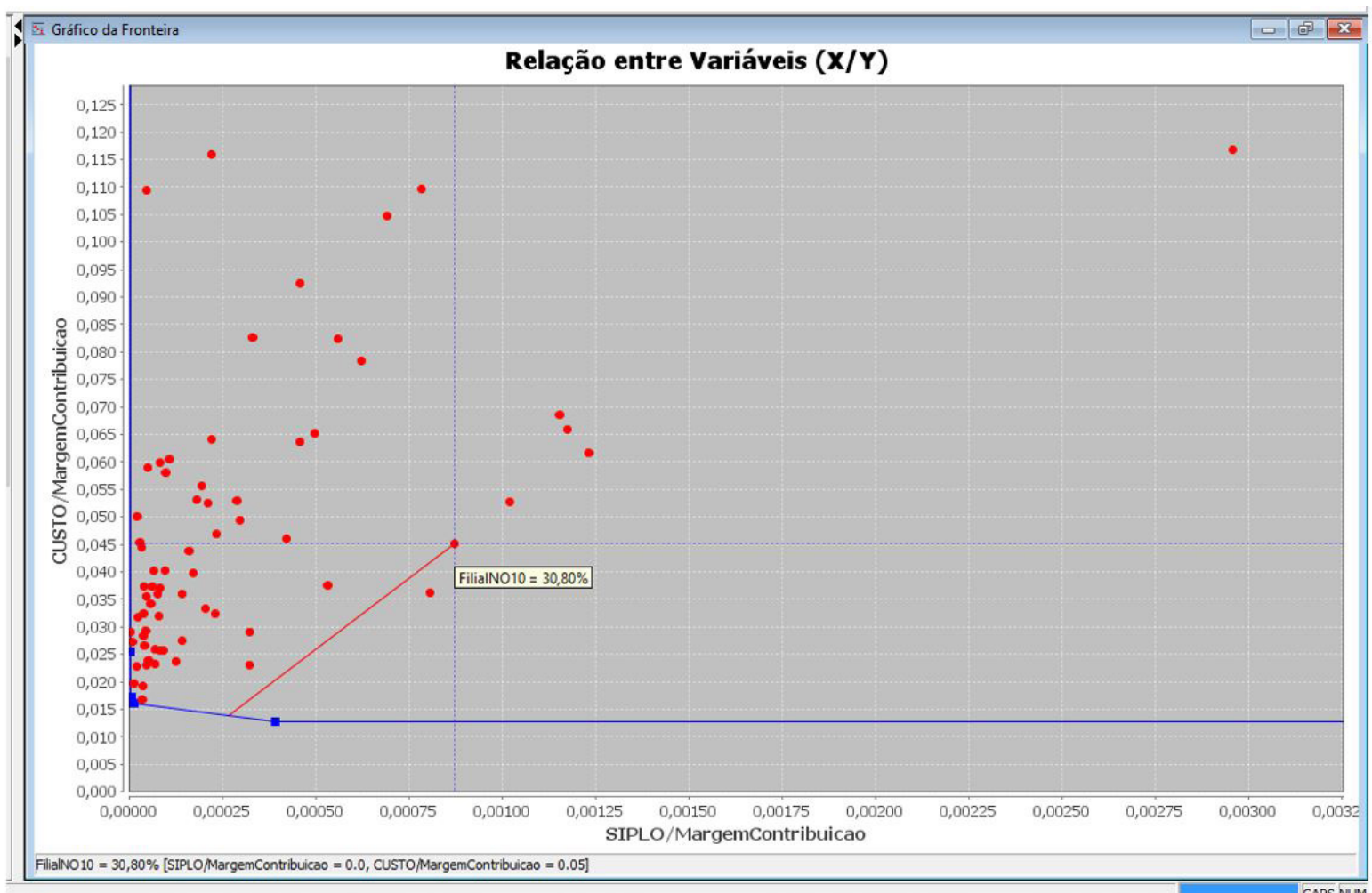

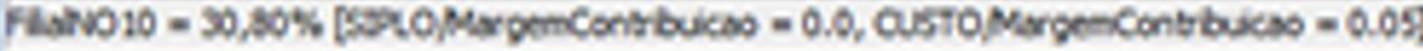

Figure 4 - Efficient Frontier Output-Oriented DEA CRS - SIPLO / Marginal Contribution X Cost /Marginal Contribution Note: GER is the Portuguese equivalent to RMO

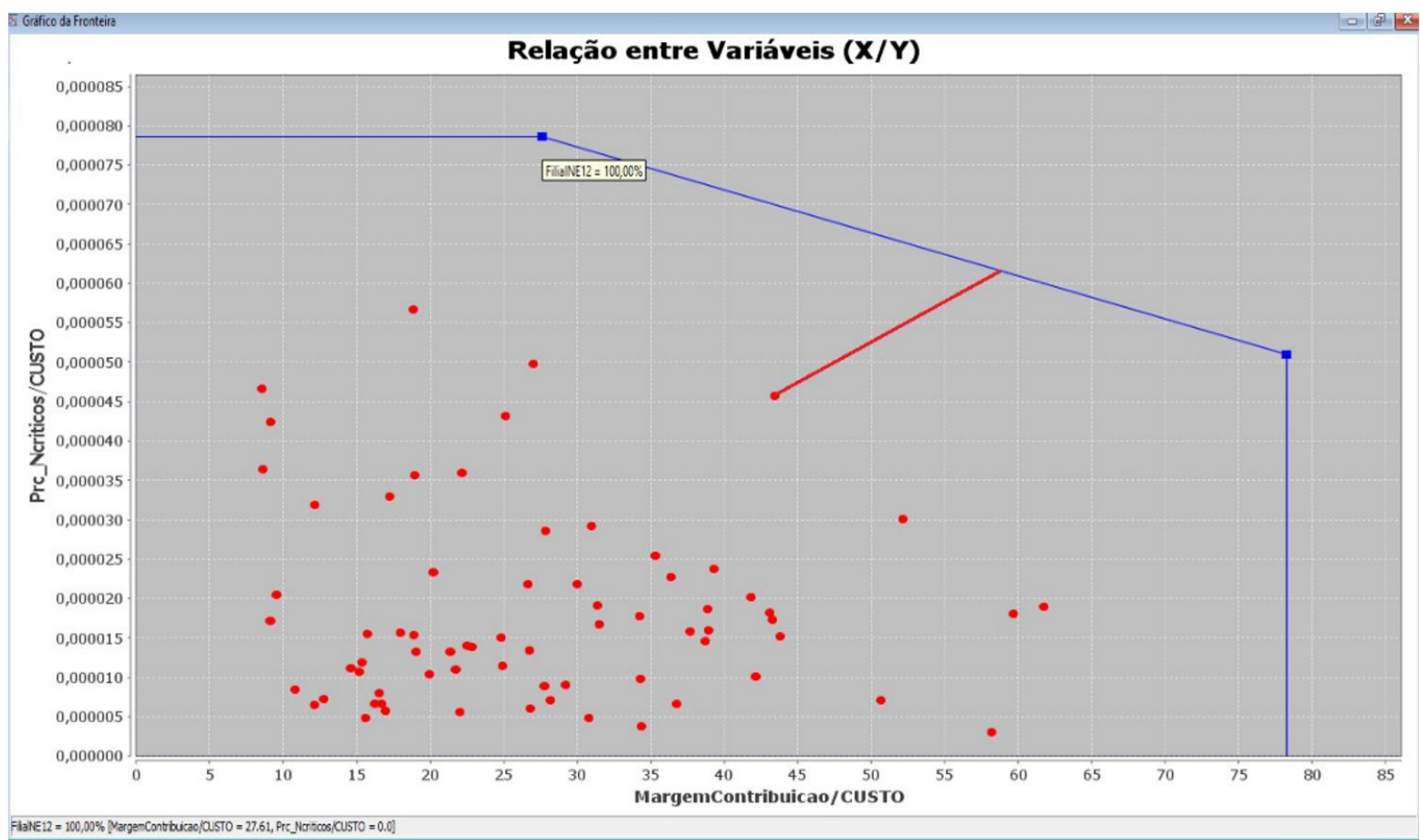

Figure 5 - Efficient Frontier Input-Oriented DEA CRS - \%_N critical / Cost X Marginal Contribution / Cost Note: GER is the Portuguese equivalent to RMO 
Table 6 - Comparing DEA VRS and CRS Efficiency Ranking - 2017

\begin{tabular}{|c|c|c|c|c|c|c|c|c|}
\hline REGIONAL & \multicolumn{2}{|c|}{ EFFICIENCY \% } & REGIONAL & \multicolumn{2}{c|}{ EFFICIENCY $\%$} & \multicolumn{2}{c|}{ REGIONAL } & \multicolumn{2}{c|}{ EFFICIENCY \% } \\
\hline OFFICE & VRS & CRS & OFFICE & VRS & CRS & OFFICE & VRS & CRS \\
\hline RMOCW01 & 100 & 100 & RMOSP09 & 100 & 62.3 & RMOSU09 & 96 & 63.2 \\
\hline RMOCW04 & 100 & 100 & RMOSU13 & 100 & 60.1 & RMOSP04 & 95.8 & 64.7 \\
\hline RMONE10 & 100 & 100 & RMONE14 & 100 & 59.4 & RMOSU03 & 95.8 & 59.6 \\
\hline RMONE12 & 100 & 100 & RMONE11 & 100 & 59.4 & RMOSP07 & 95.2 & 66.5 \\
\hline RMONE16 & 100 & 100 & RMOSE02 & 100 & 58.3 & RMOSP06 & 95.1 & 67.2 \\
\hline RMONO03 & 100 & 100 & RMOSU12 & 99.6 & 91 & RMONE05 & 94.9 & 32.3 \\
\hline RMONO04 & 100 & 100 & RMOCW05 & 99.5 & 79.7 & RMONE04 & 94.3 & 54.3 \\
\hline RMONO09 & 100 & 100 & RMOSU07 & 99.2 & 62.5 & RMOSU10 & 94 & 60.2 \\
\hline RMOSE01 & 100 & 100 & RMOSU04 & 99 & 49.5 & RMOSU11 & 94 & 49.1 \\
\hline RMOSE04 & 100 & 100 & RMONE09 & 99 & 39.7 & RMOSE03 & 94 & 42.1 \\
\hline RMOSE05 & 100 & 100 & RMOCW03 & 98.8 & 98.6 & RMONO08 & 92.7 & 84.3 \\
\hline RMOSE10 & 100 & 100 & RMONO06 & 98.5 & 60.2 & RMOSU16 & 92.3 & 60 \\
\hline RMOSP01 & 100 & 100 & RMOSP03 & 98.2 & 82.7 & RMOCW06 & 91.8 & 84.7 \\
\hline RMOSP02 & 100 & 100 & RMONE15 & 98 & 41.2 & RMONE08 & 91 & 36.8 \\
\hline RMOSP11 & 100 & 100 & RMOSU06 & 98 & 47.8 & RMONO05 & 87.1 & 70.6 \\
\hline RMOSP12 & 100 & 100 & RMOSU08 & 98 & 41.3 & RMONO01 & 87 & 30.5 \\
\hline RMOSU01 & 100 & 100 & RMONE06 & 98 & 40.1 & RMONE07 & 87 & 29.8 \\
\hline RMOSP05 & 100 & 98.9 & RMOSU15 & 97.6 & 76.6 & RMOSE12 & 85.1 & 70.1 \\
\hline RMOSE09 & 100 & 82.8 & RMOSP13 & 97.3 & 50.5 & RMONE13 & 85 & 25.3 \\
\hline RMOSU05 & 100 & 82.6 & RMOSU02 & 97 & 47.7 & RMONE02 & 84.4 & 32.3 \\
\hline RMOSE06 & 100 & 81 & RMONE03 & 96.7 & 34.6 & RMOSE07 & 82 & 43.6 \\
\hline RMOSP10 & 100 & 76.3 & RMOSP08 & 96.2 & 76.3 & RMOSE11 & 79.3 & 54.4 \\
\hline RMOCW02 & 100 & 75.4 & RMONE01 & 96 & 30.7 & RMOSE08 & 79.2 & 46.6 \\
\hline RMOSU14 & 100 & 63.6 & RMONO02 & 96 & 91.6 & RMONO07 & 76.6 & 62.4 \\
\hline
\end{tabular}

Table 7 - Cross Section 2015/2016/2017- DEA VRS Output oriented Regional Efficiency

\begin{tabular}{|c|c|c|c|c|c|c|c|c|c|c|c|}
\hline \multicolumn{4}{|c|}{ RMOCW } & \multicolumn{4}{|c|}{ RMONO } & \multicolumn{4}{|c|}{ RMONE } \\
\hline \multirow{2}{*}{$\begin{array}{l}\text { \% RMO } \\
\text { Efficient }\end{array}$} & 2015 & 2016 & 2017 & \multirow{2}{*}{$\begin{array}{l}\text { \% RMO } \\
\text { Efficient }\end{array}$} & \multirow{2}{*}{\begin{tabular}{|c|}
2015 \\
$33.33 \%$
\end{tabular}} & \multirow{2}{*}{\begin{tabular}{|c|}
2016 \\
$55.56 \%$
\end{tabular}} & \multirow{2}{*}{\begin{tabular}{|c|}
2017 \\
$33.33 \%$ \\
\end{tabular}} & \multirow{2}{*}{$\begin{array}{l}\% \text { RMO } \\
\text { Efficient }\end{array}$} & \multirow{2}{*}{$\begin{array}{c}2015 \\
31.25 \% \\
\end{array}$} & \multirow{2}{*}{$\begin{array}{c}2016 \\
25.00 \%\end{array}$} & \multirow{2}{*}{\begin{tabular}{|c|}
2017 \\
$31.25 \%$
\end{tabular}} \\
\hline & $83.33 \%$ & $83.33 \%$ & $50.00 \%$ & & & & & & & & \\
\hline RMOCW03 & 95.34\# & $100.00 *$ & 98.75\# & RMONO01 & $87.00 \#$ & $87.00 \#$ & $87.00 \#$ & RMONE14 & $100.00 *$ & $100.00 *$ & $100.00 *$ \\
\hline RMOCW01 & $100.00 *$ & $100.00 *$ & $100.00 *$ & RMONO03 & $100.00 *$ & $100.00 *$ & $100.00 *$ & RMONE07 & $87.00 \#$ & $87.00 \#$ & $87.00 \#$ \\
\hline RMOCW02 & $100.00 *$ & $100.00 *$ & $100.00 *$ & RMONO04 & $100.00 *$ & $100.00 *$ & $100.00 *$ & RMONE06 & 98.00\# & 98.00\# & $98.00 \#$ \\
\hline RMOCW04 & 100.00* & $100.00 *$ & $100.00 *$ & RMONO02 & 90.76\# & 100.00* & 96.01\# & RMONE02 & $88.18 \#$ & $84.47 \#$ & $84.35 \#$ \\
\hline RMOCW05 & $100.00 *$ & 99.55\# & 99.54\# & RMONO06 & 97.13\# & 98.46\# & 98.45\# & RMONE09 & $96.00 \#$ & $96.00 \#$ & 98.98\# \\
\hline \multirow[t]{11}{*}{ RMOCW06 } & $100.00 *$ & $100.00 *$ & 91.78\# & RMONO07 & $84.50 \#$ & 89.70\# & 76.55\# & RMONE04 & 94.31\# & 94.55\# & 94.34\# \\
\hline & & & & RMONO08 & 94.93\# & $100.00 *$ & 92.69\# & RMONE05 & $94.00 \#$ & 92.42\# & 94.90\# \\
\hline & & & & RMONO05 & $86.40 \#$ & 88.89\# & 87.14\# & RMONE13 & 85.39\# & 85.24\# & $85.00 \#$ \\
\hline & & & & RMONO09 & $100.00^{*}$ & 100.00* & $100.00^{*}$ & RMONE01 & 96.04\# & 97.25\# & 96.04\# \\
\hline & & & & & & & & RMONE03 & 95.24\# & 95.12\# & 96.74\# \\
\hline & & & & & & & & RMONE08 & 91.00\# & 91.35\# & 91.04\# \\
\hline & & & & & & & & RMONE15 & 98.41\# & 98.00\# & 98.02\# \\
\hline & & & & & & & & RMONE12 & 100.00* & $100.00 *$ & $100.00 *$ \\
\hline & & & & & & & & RMONE10 & 100.00* & 100.00* & $100.00^{*}$ \\
\hline & & & & & & & & RMONE11 & $100.00 *$ & 99.00\# & $100.00 *$ \\
\hline & & & & & & & & RMONE16 & $100.00 *$ & $100.00 *$ & $100.00 *$ \\
\hline
\end{tabular}




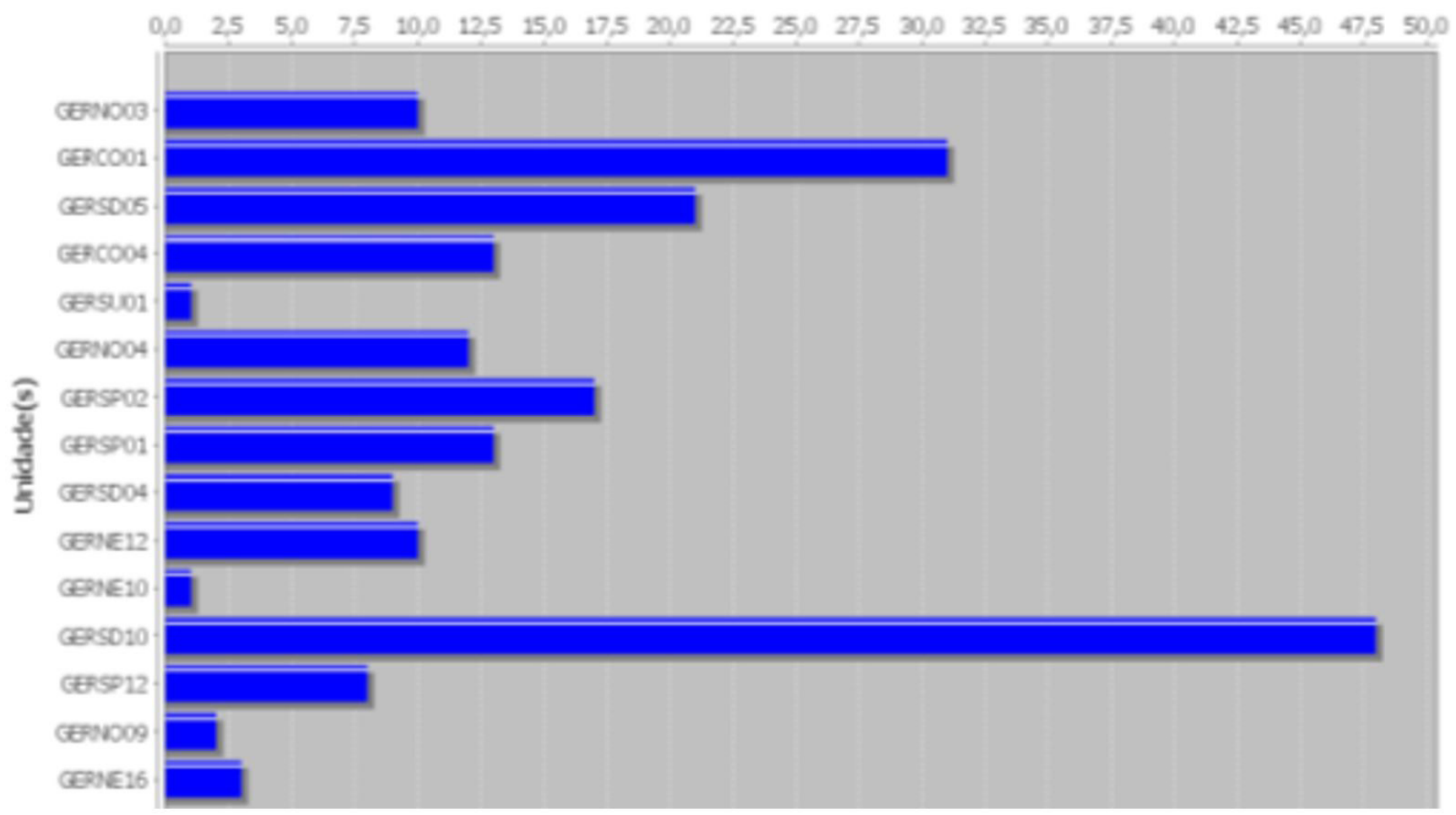

Figure 6 - Graph of Frequency of Reference of efficient RMOs - CRS model Note: GER is Portuguese abbreviation of RMO

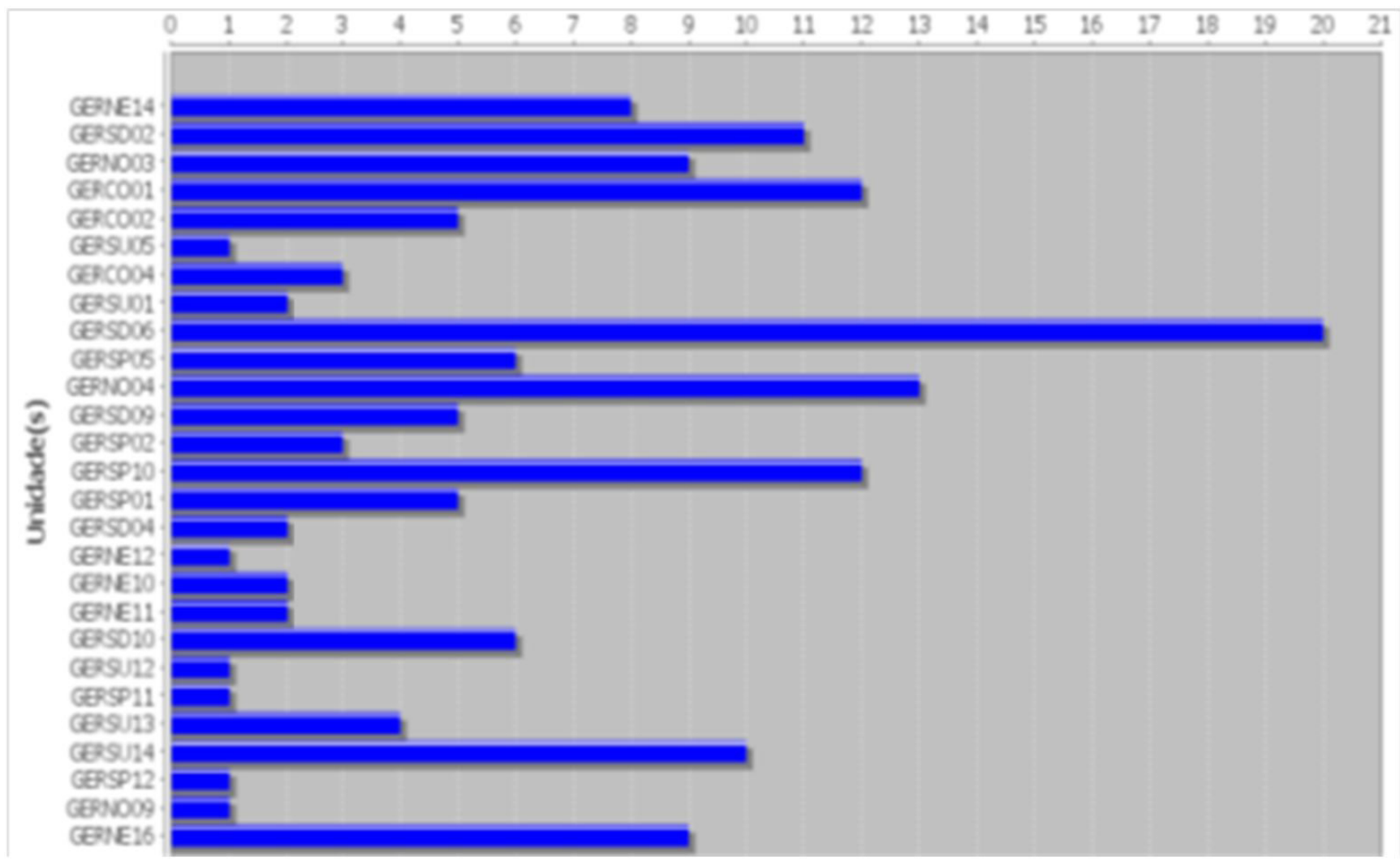

Figure 7 - Graph of Frequency of Reference of efficient RMOs - VRS model Note: GER is the Portuguese equivalent to RMO 
Table 8 - Cross Section 2015/2016/2017- DEA VRS Regional Efficiency

\begin{tabular}{|c|c|c|c|c|c|c|c|c|c|c|c|}
\hline \multicolumn{4}{|c|}{ RMOSE } & \multicolumn{4}{|c|}{ RMOSP } & \multicolumn{4}{|c|}{ RMOSU } \\
\hline \multirow{2}{*}{$\begin{array}{l}\text { \% RMO } \\
\text { Efficient }\end{array}$} & 2015 & 2016 & 2017 & \multirow{2}{*}{$\begin{array}{c}\text { \% RMO } \\
\text { Efficient }\end{array}$} & 2015 & 2016 & 2017 & \multirow{2}{*}{$\begin{array}{l}\text { \% RMO } \\
\text { Efficient }\end{array}$} & \multirow{2}{*}{$\begin{array}{c}2015 \\
37.50 \%\end{array}$} & \multirow{2}{*}{$\begin{array}{c}2016 \\
43.75 \%\end{array}$} & \multirow{2}{*}{$\begin{array}{c}2017 \\
25.00 \%\end{array}$} \\
\hline & $33.33 \%$ & $50.00 \%$ & $58.33 \%$ & & $69.23 \%$ & $69.23 \%$ & $53.85 \%$ & & & & \\
\hline RMOSE02 & 100.00* & 100.00* & 100.00* & RMOSP03 & 98.06\# & 98.05\# & 98.18\# & RMOSU16 & 92.52\# & 92.62\# & $92.25 \#$ \\
\hline RMOSE05 & 93.00\# & 92.00\# & $100.00 *$ & RMOSP13 & 99.20\# & 98.41\# & 96.83\# & RMOSU06 & 98.00\# & 98.00\# & 98.00\# \\
\hline RMOSE06 & $100.00 *$ & $100.00 *$ & $100.00 *$ & RMOSP05 & $100.00 *$ & $100.00 *$ & $100.00 *$ & RMOSU05 & $100.00 *$ & $100.00 *$ & $100.00 *$ \\
\hline RMOSE03 & 94.00\# & 94.00\# & 94.00\# & RMOSP07 & 96.53\# & 98.67\# & $95.20 \#$ & RMOSU08 & 98.00\# & 98.00\# & 98.00\# \\
\hline RMOSE07 & $85.00 \#$ & $82.00 \#$ & $82.00 \#$ & RMOSP09 & $100.00 *$ & $100.00 *$ & $100.00 *$ & RMOSU09 & 96.00\# & 96.00\# & 96.00\# \\
\hline RMOSE08 & 82.00\# & 79.00\# & 79.22\# & RMOSP02 & $100.00 *$ & $100.00 *$ & $100.00 *$ & RMOSU01 & $100.00 *$ & 100.00* & $100.00 *$ \\
\hline RMOSE09 & 99.00\# & $100.00 *$ & $100.00 *$ & RMOSPO4 & $100.00 *$ & $100.00 *$ & 95.84\# & RMOSU03 & $9.51 \#$ & $100.00 *$ & 95.80\# \\
\hline RMOSE01 & 4.46\# & $100.00 *$ & $100.00 *$ & RMOSP10 & $100.00 *$ & $100.00 *$ & $100.00 *$ & RMOSU10 & 95.01\# & 94.00\# & $94.00 \#$ \\
\hline RMOSE04 & 100.00\# & $100.00 *$ & $100.00 *$ & RMOSP06 & 95.10\# & 95.00\# & 95.05\# & RMOSU11 & 94.63\# & 94.00\# & 94.00\# \\
\hline RMOSE11 & 84.05\# & 83.98\# & $79.28 \#$ & RMOSP01 & $100.00 *$ & $100.00 *$ & $100.00 *$ & RMOSU15 & $100.00 *$ & 100.00* & 97.55\# \\
\hline RMOSE12 & 95.00\# & $85.00 \#$ & $85.00 \#$ & RMOSP08 & $100.00 *$ & $100.00 *$ & 96.17\# & RMOSU04 & 99.00\# & 99.00\# & 99.00\# \\
\hline RMOSE10 & 100.00\# & 100.00* & $100.00 *$ & RMOSP11 & $100.00 *$ & 100.00* & $100.00 *$ & RMOSU02 & 96.27\# & 97.85\# & 97.02\# \\
\hline & & & & RMOSP12 & $100.00 *$ & $100.00 *$ & $100.00 *$ & RMOSU07 & 99.00 & 99.00\# & 99.00\# \\
\hline & & & & & & & & RMOSU12 & $100.00 *$ & $100.00 *$ & 99.56\# \\
\hline & & & & & & & & RMOSU13 & $100.00 *$ & 100.00* & $100.00 *$ \\
\hline & & & & & & & & RMOSU14 & $100.00 *$ & $100.00 *$ & $100.00 *$ \\
\hline
\end{tabular}

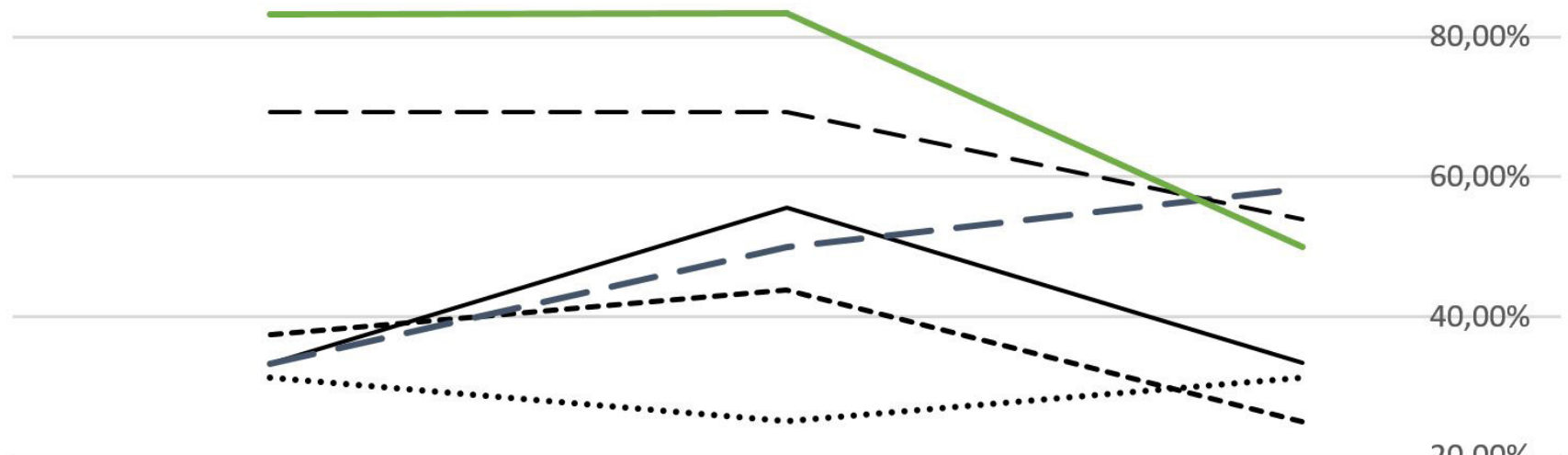




\subsection{Phase 2 - Treatment}

The great innovative differential of PerformerDEA is the simulation function of new targets. From the definition of the organizational production benchmark frontier, it establishes the improvement actions, which must be submitted to the unit evaluated.

At the Treatment Phase a simulation was implemented with application of PerfomerDEA software with PMM MODEL generate graphs analysis, to be used on managerial simulations, performed from the characteristics of the corporate environment and market framed according to the objectives, already outlined for this case study.

To exemplify the instrumental potential of the proposal approach, was made a simulation applied to RMONOO8 panel data results corresponding to the year 2015 according to the DEA VRS Output-oriented model.
Refer to Figure 9, upper box at the right side, it is verified that the RMONO08 has an efficiency equal to $94.93 \%$ and referred to Table 7 at intermediary column RMONO 2015 line. It is interesting to note that the modeling pointed as efficient reference units: RMONO03; RMONO04 and RMONO09 of the same Macro Region and RMOCW02 of the neighboring Macro Region, refer to Table 7 and Figure 2. It is important to note that the model autonomously maps the references.

Figure 9, blue text highlighted on left column, shows the comparison of RMONO08 with RMONO03 relating the percentage consumed by RMONO03 for the three inputs - Def. Habit x 1000 / Area, SIPLO and Cost in relation of RMON08 and for production relating the percentage produced by RMONO03 for the three outputs - Contribution Margin, Non-Critical Prc and FORA in relation of RMON08.

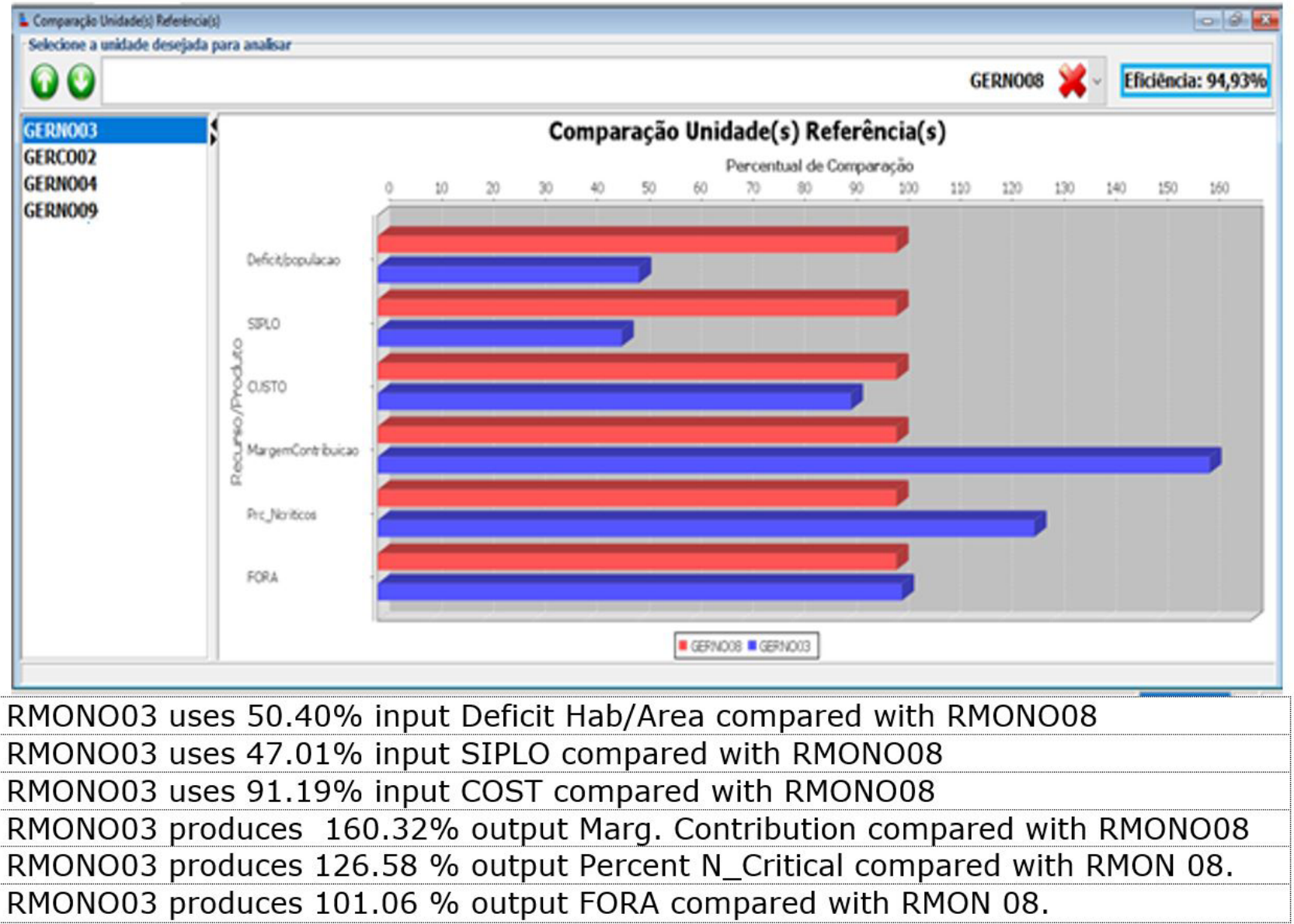

Figure 9 - Comparing RMO References with RMONO08 2015 - VRS Output-oriented Note: GER is the Portuguese equivalent to RMO 
Figure 10, blue text highlighted on left column, shows the comparison of RMONO08 with RMONO04 relating the percentage consumed by RMONO04 for the three inputs - Def. Habit x 1000 / Area, SIPLO and Cost in relation of RMON08 and for production relating the percentage produced by RMONO04 for the three outputs - Contribution Margin, Non-Critical Prc and FORA in relation of RMON08. These applications shall be repeat comparing RMONO08 others reference identified efficient RMOs (RMOCW02 and RMONO09), see Figures 9 and 10 - left column not highlighted RMOs.

Figure 11 represents the relative importance in RMONO08's efficiency budget according to each input and output, with reference to RMONO03, RMOCW02, RMONO04 and RMONO09.

One of the most powerful pieces of information that is output by the DEA analysis is the set of target factor values for those units assessed as inefficient. The main innovation and functionality of Performer DEA, since it allows the simulation to establish targets to each RMO become efficient mirrored at efficient RMO references.

Figure 12 (see Target and Improvement columns) shows the potential improvement targets that RMON08 must be submitted to become efficient. Target of SIPLO input $=2.045 .677$ with reduction of $47.07 \%$ (see Improvement column). Increase in outputs: Target of
Margin Contribution $=10.543 .921$ increase of $5.3 \%$; Prc_Ncríticos $=99,792$ increase of $26.3 \%$, e; OUT $=99,017$ increase of $6.3 \%$.

By simulation we introduce a virtual unit called META (TARGET) in the modeling. META (TARGET) has the same values of the basket of three inputs for three outputs, as stipulated for the Target and Improvement columns to RMONO08 in Figure 12 - Potential Improvement RMONO08 - 2015- VRS Output- oriented. When running the model, the META virtual unit has efficiency equal to $100 \%$. META has efficiency achieved of $100 \%$, it represents the projection of RMONO08 in the Benchmarking Frontier of the 72 RMO. This PerformerDEA software capacity of projection of Meta is visualized in Figure 4, see that the projection of inefficient unit is the point formed by the intersection of the red line with blue line of efficient frontier. Refer to Figure 5, the point represented by the red line intercepting the continuous line of efficient frontier.

It should be emphasized that the simulation through the virtual unit META, allows imposing the efficient RMO production targets superior to those reached. This procedure promotes the changing of the originally modeled benchmarking boundary. In this way, performance management becomes operationally a continuous mode, to be improved through the best self-knowledge of the Institution processes.

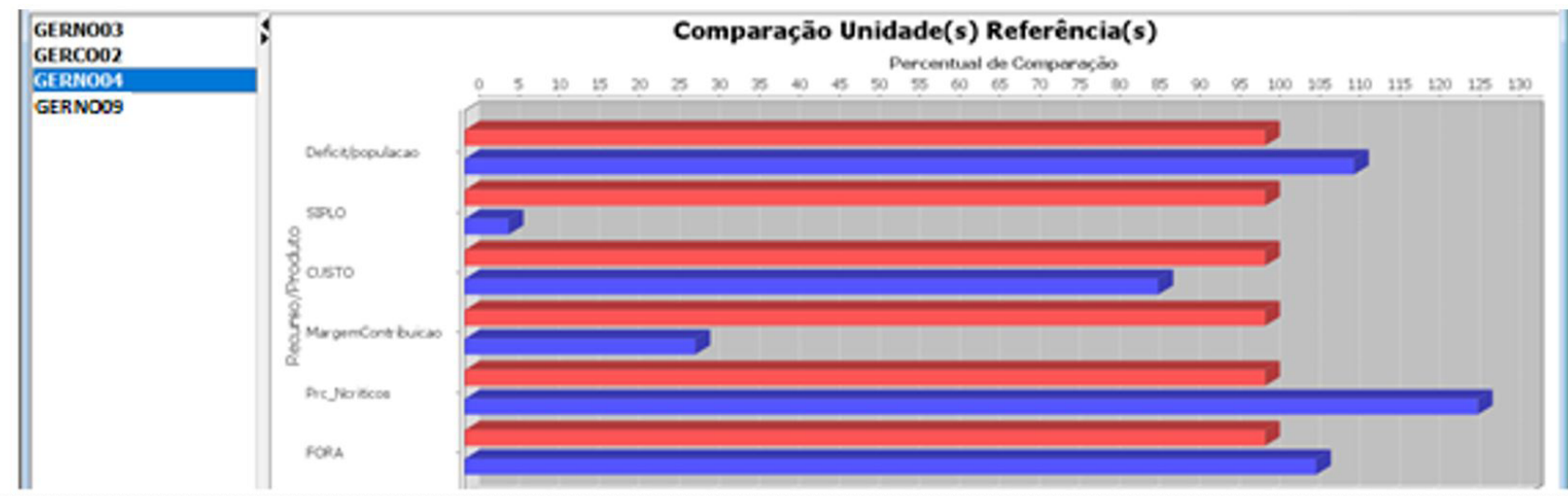

RMONO04 uses $111.11 \%$ input Deficit Hab/Area compared with RMONO08

RMONO04 uses $5.48 \%$ input SIPLO compared with RMONO08

RMONO04uses $86.67 \%$ input COST compared with RMONO08

RMONO04 produces $28.81 \%$ output Marg. Contribution compared with RMONO08

RMONO04 produces $126.58 \%$ output Percent N_Critical compared with RMON 08. RMON 04 produces $106.38 \%$ output FORA compared with RMON 08.

Figure 10 - Comparing RMO References with RMONO08 2015 - VRS Output-oriented Note: GER is the Portuguese equivalent to RMO 


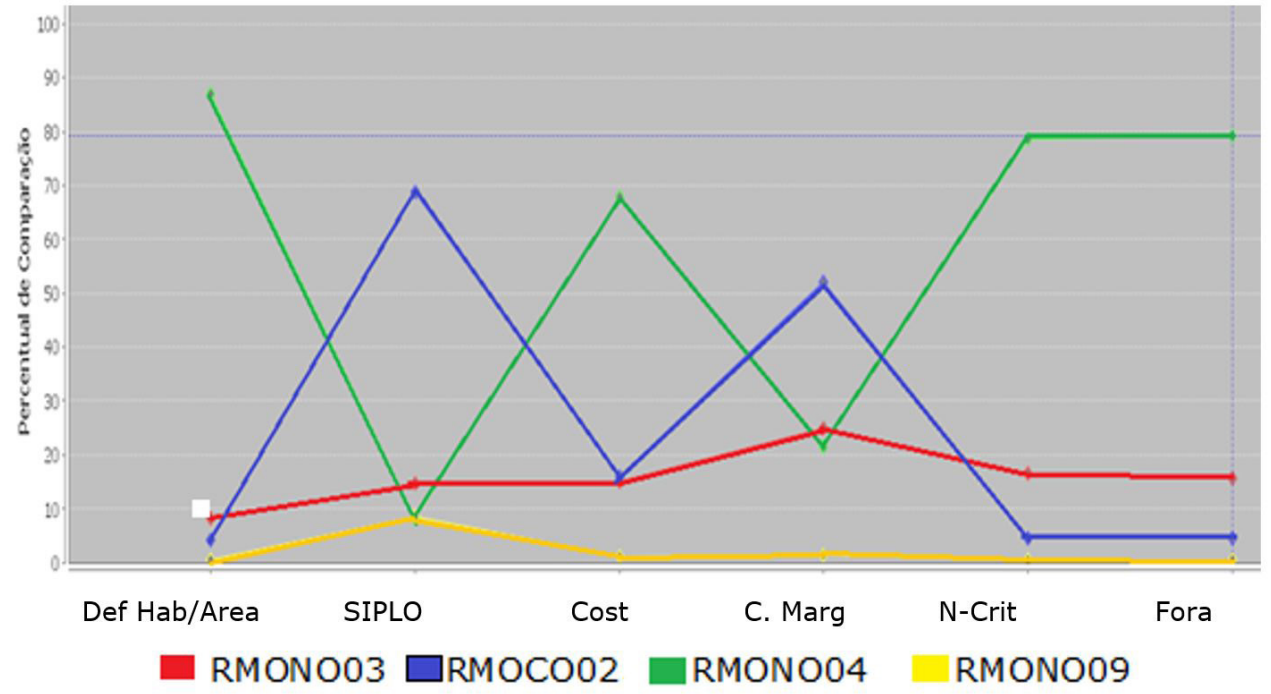

Figure 11 - Relative Budget RMONO08 by Reference Efficient RMO Input /Output - 2015 VRS Output-oriented Note: GER is the Portuguese equivalent to RMO

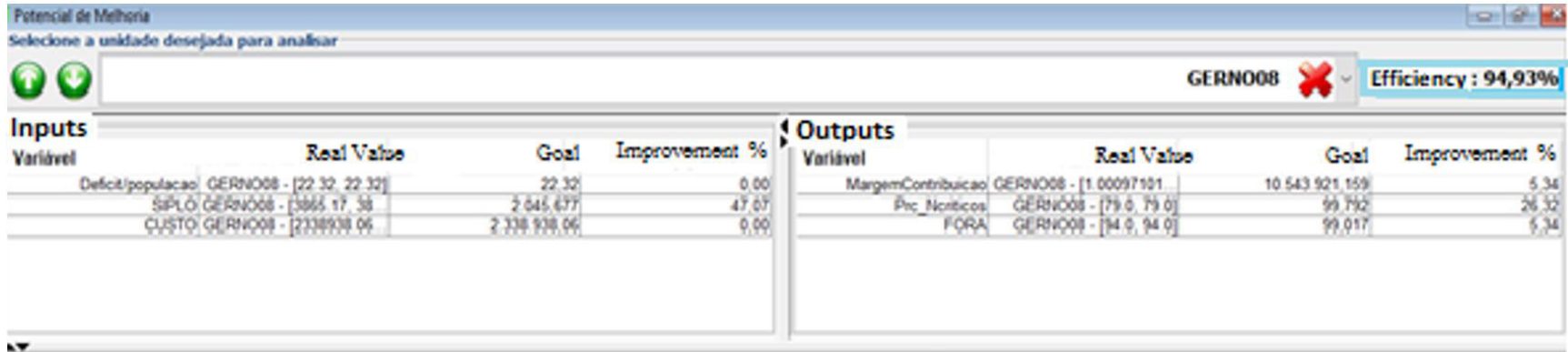

GRAPH OF POTENTIAL OF IMPROVEMENT Percesteal of Potestial of Improvemest

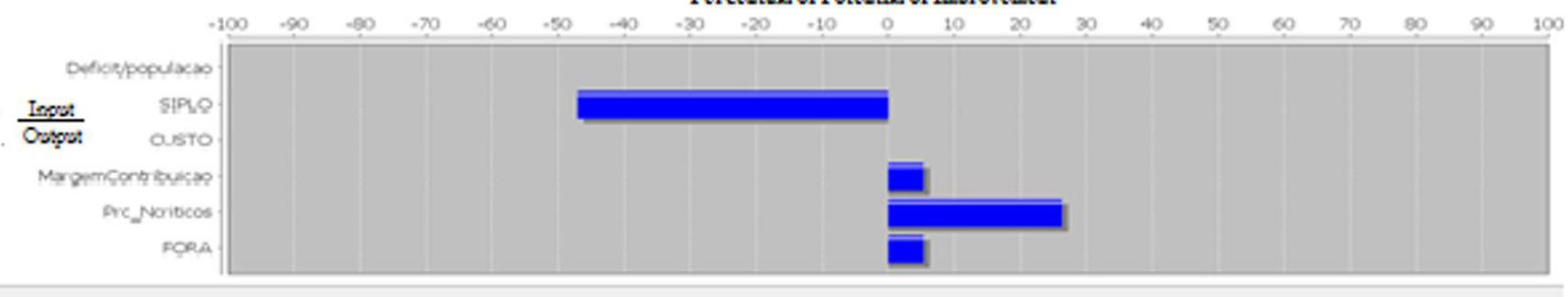

Figure 12 - Potential Improvement RMONO08 - 2015- VRS Output-oriented Model Note: GER is the Portuguese equivalent to RMO

The potential of the methodology in the local management is that can show the improvement of performance of each unit by the graphs generated, them was mirrored for its efficient units of reference. They show to the manager on what is happening in the RMOs that are references to them, in order to allow more adherent management with the corporate conditions.

Another relevance to be observed is that the modeling presented for each RMO allows the creation of seventy-two times more graphs such as those generated. 
Table 9 - Lenses of Systemic Analysis

\begin{tabular}{|c|l|}
\hline Approach Lens & $\begin{array}{l}\text { Measurement of efficiency - refer to section } 3 \\
\text { Endogenous inputs or environmental variables - refer to section } 5.1 \S 2^{\circ} \text { and Figure } 3 .\end{array}$ \\
\hline Singularity Lens & Evolve and adapt to changes by simulations - refer to section $5.1 \S 4^{\circ}$; Figure 4 to 5 and Table 6. \\
\hline Identification Lens & $\begin{array}{l}\text { Continuous self-knowledge by reference units in a holistic view - refer to section } 5.1 \S 5^{\circ} \text { to } 6^{\circ} ; \text { Figure } 6 \text { to } 8 \text { and } \\
\text { Table } 7 \text { to } 8 .\end{array}$ \\
\hline Measuring Lens & $\begin{array}{l}\text { Application and processing in achieving performance goals - refer to section } 5.1 \text { and Table } 4 ; \text { section } 5.2 \text { and } \\
\text { Figure 9 to } 10 .\end{array}$ \\
\hline Management Lens & $\begin{array}{l}\text { Diagnoses strengths and weaknesses and establish performance improvement action - refer to section } 5.2 \text { and } \\
\text { Figure } 11 \text { to } 12 .\end{array}$ \\
\hline Integration Lens & $\begin{array}{l}\text { Application and processing view just in time - refer to section } 3 \text { - proposal an integration with Digital Corporate } \\
\text { Database Platform. }\end{array}$ \\
\hline
\end{tabular}

\section{CONCLUSIONS}

The model presented was aimed at demonstrating the functionalities that the integration of digital data platform with the analytical software Performer DEA promotes in order to instrumentalize the performance management for the managerial units of a financial institution. This conclusion is emphasized by the proof of it was improved the six Lens of Systemic Analysis proposed by VALMORBIDA, ENSSLIN, 2016, refer to Table 1, to testify the quality and effectiveness of this PMM approach.

The six lenses of improvements portraited and promoted by PMM are referred at table 9 .

Summarily, the macro view of the available data set, related to the 72 Regional Management (RMO) of the institution allowed:

a) to determine the set of inputs and outputs considered for performance management purposes;

b) to opt for the adoption of the DEA model of variable returns of scale (VRS), in order to consider in the analysis, the huge differences in size and market environment between units and that, of course, greatly affect the productivity scale;

c) to explain the complexity and magnitude of environment analyzed by a dynamic process from data mining algorithm linked with an analytic software of performance measurement and management.

d) on turning feasible the challenge accounting of capture of data from corporate real estate activities carried out by engineers, architects and administration staff of $72 \mathrm{RMO}$, distributed in all Brazilian territory.

e) to portrait in a performance model the diversified activities of each regional staff take for analyze, approval of the feasibility and monitoring of investment in the construction of housing developments and of isolated habitation units.

The selection of the data and its treatment by the software allowed us to determine the efficient RMOs, the feasible frontier of production and the classification of the units analyzed according to their efficiency (ranking).

Besides this, it was possible to establish the number of occurrences in which an efficient RMO is a reference to the others, thus measuring the potential that it has within the institution to serve as a paradigm for other units.

Inversely, we identified the set of efficient units which determine the benchmarking frontier relative to a particular RMO, establishing these is very important for a comparative analysis and, in the direct comparison, the variables that are the most important, either input or output.

A cross-section analysis of the temporal variation of efficiencies in the years 2015, 2016 and 2017 was also carried out, in order to allow an analysis of the evolution of the management in each RMO, as well as the evolution of the number of efficient units in each macro-region and also in the whole country.

Finally, it was presented the possibility of setting targets for each RMO, in order to make it an efficient unit.

It is evident that these approach does not present answers and immediate solutions to the modifications that an RMO must carry out in its processes, so that it will become immediately an efficient unit. The best performance will be conquest by a continuous knowledge of the interactions of the use of inputs promote on output gains. The advantage of this method is that it identifies the relations of the use of inputs and outputs that promote efficiency, on observing the efficient offices which should serve as paradigm for the improvement of the performance of an inefficient RMO. 
Next steps, a challenge for research is consider the approach developed by Tabatabaei and Bazrkar (2019), on observe the criticized DEA flexibility in the selection of input and output weights and its self-evaluation nature, to be counteract by using the cross-efficiency model.

Examining the work process of the units which make up the benchmark of a specific RMO, it is possible to evaluate whether or not good practices that led to the reduction of an input or the increase of a product in an efficient RMO can be adopted in the unit which is under study.

Another advantage of this method is that the targets to be defined by the manager are no longer arbitrary, they become feasible, because they will be based on concrete experiences existing in the institution itself.

The proposed use of the presented PMM system in the way of complement the current organizational effectiveness performance process, will support the necessary and fundamental aspect, with account of the resources disposable to comply with the efficiency standards required in a more and more competitive banking market.

\section{REFERENCES}

Banker, R.D. and Morey, R.C. (1986), "Efficiency analysis for exogeneously fixed inputs and outputs", Operations Research, Vol. 34, No. 4, pp. 513-21. http://dx.doi.org/10.1287/ opre.34.4.513.

Banker, R.D., Charnes, A.W. and Cooper, W.W. (1984), "Some models for estimating technical and scale inefficiencies in data envelopment analysis", Management Science, Vol. 30, No. 9, pp. 1078-92.

Bititci, U., Garengo, P., Dörfler, V. et al. (2012), “Performance measurement: challenges for tomorrow", International Journal of Management Reviews, Vol. 14, pp. 305-27. http:// dx.doi.org/10.1111/j.1468-2370.2011.00318.

Bourne, M., Kennerley, M. and Franco-Santos, M. (2005), "Managing through measures: a study of impact on performance", Journal of Manufacturing Technology Management, Vol. 16, No. 4, pp. 373-95.

Camioto, F., Mariano, E. and Rebelatto, D. (2017), "Sustainability improvement opportunities in Brazilian sectors: analysis of DEA slacks", Brazilian Journal of Operations \& Production Management, Vol. 14, No. 3, pp. 363-70. http:// dx.doi.org/10.14488/BJOPM.2017.v14.n3.a9.
Charnes, A.W., Cooper, W.W. and Rhodes, E.L. (1978), "Measuring the efficiency of decision-making units", European of Operational Research, Vol. 2, No. 6, pp. 429-44.

Coelli, T., Prasada Rao, D.S., O’Donnell, C.J. et al. (2005), Am Introduction to Efficiency and Productivity Analysis, 2nd ed., Springer Science \& Business Media, New York, available at: http://www.utdallas.edu/ ryoung/phdseminar/CCR 1978 .pdf

Fethi, M.D. and Pasiouras, F. (2010), "Assessing bank performance with operational research and artificial intelligence techniques: a survey", International Journal of Engineering Science and Technology, Vol. 204, pp. 189 - 198.

Franco, M.A.J., Ensslin, S.R. and Gasparetto, V. (2016), "Avaliação de desempenho de custos logísticos: análise da literatura para levantamento de futuras pesquisas", in XXIII Congresso Brasileiro de Custos, Porto de Galinhas.

Gunasekaran, A., Williams, H.J. and Mcgaughey, R.E. (2005), "Performance measurement and costing system in new enterprise", Technovation, Vol. 25, No. 5, pp. 523-33.

Kholghi, M. and Keyvanpour, M. (2011), "An analytical framework for data stream mining techniques based on challenges and requirements", International Journal of Engineering Science and Technology, Vol. 3, No. 3, pp. 2011.

Koota, P. and Takala, J. (1998), “Developing a performance measurement system for world-class distribution logistics by using activity-based costing and management: case: basic metal industries", International Journal of Technology Management, Vol. 16, No. 1-3, pp. 267-80. http://dx.doi. org/10.1504/IJTM.1998.002653.

Maniati, M. and Sambracos, E. (2017), "Measuring the technical efficiency for the shipping banks: an approach using data envelopment analysis", Theoretical Economics Letters, Vol. 7, No. 3, pp. 1-15.

Melnyk, S.A., Bititci, U., Platts, K. et al. (2014), "Is performance measurement and management fit for the future", Management Accounting Research, Vol. 25, pp. $173-86$

Novaes, L.F.L., Fraga, A.F. and Novaes, M.R.L. (2012), "Aplicação de software na gestão do desempenho", in VIII Congresso Nacional de Excelência de Gestão, Inovarse, Rio de Janeiro, available at: www.inovarse.org/sites/default/files/ T12 0512 2829.pdf

Novaes, L.F.L., Fraga, A.F., Novaes, M.M.R.L. et al. (2018), "Double perspective DEA on appraising property's fair market 
value by Brazilian Standards - Central European", Review of Economics and Management, Vol. 2, No. 4, pp. 39-89.

Nudurupati, S.S., Bititci, U.S., Kumar, V. et al. (2011), States of the art literature review on performance measurement", Journal Computers \& Industrial Engineering, Vol. 60, No. 2, pp. 279-90.

Okwir, S. (2018), "Performance measurement and management systems: a perspective from complexity theory international", Journal of Management Reviews, Vol. 20, No. 3, pp. 731-54.

PerformerDEA. (2019), Software of Measurement and Management Performance, Data Envelopment Analysis, available at: http://app.avalsoft.com.br/

Ray, S.C. (2004), Data Envelopment Analysis: Theory and Techniques for Economics and Operations Research, 1st ed., Cambridge University Press, USA, pp. 307-326.

Schiehll, E. and Morissette, R. (2000), "Motivation, measurement and rewards from a performance evaluation perspective", Revista de Administração Contemporânea, Vol. 4, No. 3, pp. 7-24.

Tabatabaei, M.H. and Bazrkar, A. (2019), Providing a model for ranking suppliers in the sustainable supply chain using cross efficiency method in data envelopment analysis, Brazilian Journal of Operations \& Production Management, Vol. 16, No. 1, pp. 43-52, available at: https:// bjopm. emnuvens.com.br/bjopm/article/view/593

Valle, G.N. (2019), Consolidated Interim Financial Statements at September 30, 2018 and Report on Review, PWC, Brasília, available at: http://www.caixa.gov.br/ Downloads/caixa-governanca/CAIXA_DFsIngles092018_Final. pdf

Valmorbida, S.M.I. and Ensslin, L. (2016), "Knowledge building on performance evaluation for organizational management: an investigation in international scientific research", Contemporary Journal of Accounting, Vol. 13, No. 28, pp. 123-48.

Received: 15 Dez 2018

Approved: 02 Jan 2020

How to cite: Novaes, L.F.L., Paiva, S.A., Barbosa, F.M. et al. (2020), “Applied Research on Banking Production Planning and Control in the Housing Investment Process", Brazilian Journal of Operations \& Production Management, Vol. 17, No. 1, e2020687. https://doi.org/10.14488/BJOPM.2020.012 